\title{
Nanofibrous poly(lactide-co-glycolide) membranes loaded with diamond nanoparticles as promising substrates for bone tissue engineering
}

This article was published in the following Dove Press journal:

International Journal of Nanomedicine

17 April 2012

Number of times this article has been viewed

\author{
Martin Parizek' \\ Timothy EL Douglas ${ }^{2}$ \\ Katarina Novotna' \\ Alexander Kromka ${ }^{3}$ \\ Mariea A Brady ${ }^{4}$ \\ Andrea Renzing ${ }^{4}$ \\ Eske Voss ${ }^{4}$ \\ Marketa Jarosova ${ }^{3}$ \\ Lukas Palatinus ${ }^{3}$ \\ Pavel Tesarek ${ }^{5}$ \\ Pavla Ryparova ${ }^{5}$ \\ Věra Lisa \\ Ana M dos Santos ${ }^{2}$ \\ Lucie Bacakova' \\ 'Department of Biomaterials and Tissue \\ Engineering, Institute of Physiology, Academy \\ of Sciences of the Czech Republic, Prague, \\ Czech Republic; ${ }^{2}$ Polymer Chemistry and \\ Biomaterials Group, Ghent University, Ghent, \\ Belgium; ${ }^{3}$ Institute of Physics, Academy of \\ Sciences of the Czech Republic, Prague, \\ Czech Republic; ${ }^{4}$ Department of Oral and \\ Maxillofacial Surgery, University of Kiel, Kiel, \\ Germany; ${ }^{5}$ Czech Technical University in \\ Prague, Faculty of Civil Engineering, Prague, \\ Czech Republic
}

\section{Video abstract}

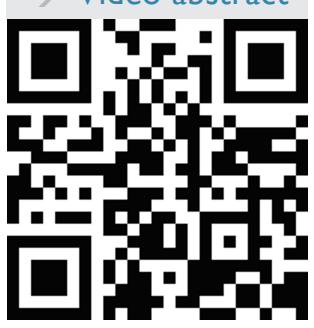

\section{Point your smartphone at the $\mathrm{QR}$ code to the left. If you have a $Q R$ code reader the video abstract will appear. Or use http: //dvpr.es/ vbovIf}

Correspondence: Lucie Bacakova Department of Biomaterials and Tissue Engineering, Institute of Physiology, Academy of Sciences of the Czech Republic, Videnska 1083, 14220 Prague 4-Krc,

Czech Republic

Tel +420296443743

Fax +420296442488

Email lucy@biomed.cas.cz
Background: Nanofibrous scaffolds loaded with bioactive nanoparticles are promising materials for bone tissue engineering.

Methods: In this study, composite nanofibrous membranes containing a copolymer of L-lactide and glycolide (PLGA) and diamond nanoparticles were fabricated by an electrospinning technique. PLGA was dissolved in a mixture of methylene chloride and dimethyl formamide (2:3) at a concentration of $2.3 \mathrm{wt} \%$, and nanodiamond (ND) powder was added at a concentration of $0.7 \mathrm{wt} \%$ (about $23 \mathrm{wt} \%$ in dry PLGA).

Results: In the composite scaffolds, the ND particles were either arranged like beads in the central part of the fibers or formed clusters protruding from the fibers. In the PLGA-ND membranes, the fibers were thicker (diameter $270 \pm 9 \mathrm{~nm}$ ) than in pure PLGA meshes (diameter $218 \pm 4 \mathrm{~nm}$ ), but the areas of pores among these fibers were smaller than in pure PLGA samples $\left(0.46 \pm 0.02 \mu \mathrm{m}^{2}\right.$ versus $1.28 \pm 0.09 \mu \mathrm{m}^{2}$ in pure PLGA samples). The PLGA-ND membranes showed higher mechanical resistance, as demonstrated by rupture tests of load and deflection of rupture probe at failure. Both types of membranes enabled the attachment, spreading, and subsequent proliferation of human osteoblast-like MG-63 cells to a similar extent, although these values were usually lower than on polystyrene dishes. Nevertheless, the cells on both types of membranes were polygonal or spindle-like in shape, and were distributed homogeneously on the samples. From days 1-7 after seeding, their number rose continuously, and at the end of the experiment, these cells were able to create a confluent layer. At the same time, the cell viability, evaluated by a LIVE/DEAD viability/cytotoxicity kit, ranged from $92 \%$ to $97 \%$ on both types of membranes. In addition, on PLGA-ND membranes, the cells formed well developed talin-containing focal adhesion plaques. As estimated by the determination of tumor necrosis factor-alpha levels in the culture medium and concentration of intercellular adhesion molecule-1, MG-63 cells, and RAW 264.7 macrophages on these membranes did not show considerable inflammatory activity.

Conclusion: This study shows that nanofibrous PLGA membranes loaded with diamond nanoparticles have interesting potential for use in bone tissue engineering.

Keywords: nanofibers, nanoparticles, electrospinning, nanotechnology, regenerative medicine, human bone cells

\section{Introduction}

Nanofibrous scaffolds have recently been recognized as promising cell carriers for advanced tissue engineering. This is mainly due to the fact that these scaffolds closely mimic the structure of the fibrous component of the native extracellular matrix formed by nano fibers of collagen, elastin and other proteins. In general, nano structured substrates are considered to be advantageous for cell adhesion and growth. 
In comparison with conventionally used flat or micro structured cell growth supports, nano structured carriers improve the cell-matrix interaction, eg, by adsorption of cell adhesion-mediating molecules from biological fluids in an appropriate geometrical conformation, which enables good accessibility of specific active sites on these molecules to cell adhesion receptors. ${ }^{1,2}$ In addition, the application of nano structured substrates can be particularly advantageous in bone tissue engineering. The reason is that from all cell adhesion-mediating molecules, these substrates preferentially adsorb vitronectin, which is recognized mainly by osteoblasts, rather than other cell types (eg, vascular endothelial and smooth muscle cells or fibroblasts). ${ }^{2}$

Nanofibrous scaffolds have been prepared mainly from natural or synthetic polymers, such as collagen and elastin, ${ }^{3}$ silk fibroin, ${ }^{4}$ chitosan, ${ }^{5}$ peptides with ligands for cell adhesion receptors, ${ }^{6}$ polyurethane, ${ }^{7}$ polycaprolactone, ${ }^{8}$ polylactide ${ }^{9}$ and particularly its copolymers with polyglycolide. ${ }^{10-15}$

In our earlier studies, and also in studies by other authors, poly (lactide-co-glycolide) (PLGA) has proved to be an appropriate material for the construction of porous and fibrous scaffolds for bone tissue engineering. ${ }^{16}$ In comparison with pure polylactic acid (PLA), the PLGA copolymer is less brittle, and in comparison with pure polyglycolide is less degradable (ie, less prone to hydrolytic degradation). Thus, PLGA provides more stable support for bone tissue regeneration, which lasts several weeks in human beings. In addition, this material has been approved by the Food and Drug Administration for medical use, including implantation into human tissues.

The main methods of nanofiber preparation are selfassembly, liquid phase separation, template synthesis, drawing, and predominantly electrospinning. ${ }^{17,18}$ Electrospinning is a novel and effective fabrication process that uses an electric field to control the deposition of polymer fibers onto a target substrate. This electrostatic processing strategy can be used to fabricate non woven fibrous polymer meshes composed of diameters ranging from several microns down to $100 \mathrm{~nm}$ or less, which mimic the hierarchically organized microstructure and nanostructure of the natural tissues..$^{9,19}$

However, the mechanical properties and bioactivity of polymer-based nanofibrous scaffolds are often unsatisfactory for tissue engineering. Some modifications of these scaffolds are therefore necessary. For example, PLA scaffolds were reinforced by copolymerization of PLA with functionalized polyaniline, which also endowed these scaffolds with electrical conductivity and antimicrobial activity. ${ }^{20,21}$ In the case of scaffolds intended for the construction of bioartificial bone, hydroxyapatite and tricalcium phosphate have been used, because they occur in the inorganic component of the natural bone matrix. On bioactive nanofibers, these minerals can be deposited spontaneously in simulated biological fluids ${ }^{22}$ or they can be incorporated into the nanofibers during the preparation process. ${ }^{9-15}$ In some studies, mineral nanoparticles have been substituted by other nanosized materials, eg, by carbon nanotubes incorporated inside polylactide nanofibers. ${ }^{17,23}$ Despite many advantageous properties of carbon nanotubes, such as excellent mechanical properties and electrical conductivity, which can enhance bone tissue regeneration, carbon nanotubes have repeatedly been shown to be associated with a risk of cytotoxicity, genotoxicity, and tumorigenicity. ${ }^{24,25}$ Diamond nanoparticles are an alternative promising component of nanofibrous membranes. In numerous studies, they have displayed very high biocompatibility and no considerable cytotoxicity. In the form of films deposited on the biomaterial surface, nanocrystalline diamond provides excellent growth support for various cell types, particularly bone-derived cells. ${ }^{26-28}$ In the form of dispersed nanoparticles, they have been shown not to interfere with gene expression, protein synthesis, cell cycle progression, and differentiation of cells in vitro, although they were taken up into cells via clathrin-mediated endocytosis. ${ }^{29}$ In future uses of composite polymer-nanodiamond (ND) scaffolds in vivo, the ND particles could be cleared from the organism by glomerular filtration after degradation of the scaffolds, as is possible in the case of carbon nanotubes. ${ }^{30,31}$

In a recent study by Behler et al, ${ }^{32}$ nanocrystalline diamond particles were incorporated into polyacrylonitrile or polyamide nanofibers and microfibers. However, these nanofibers were characterized only for their physical and chemical properties and were designed for use in technical applications, such as protection against ultraviolet light and improved scratch resistance of the material surfaces. In another study, diamond nanoparticles were incorporated into polymeric films, and the effects of this composite material on the growth of osteoblasts was evaluated. ${ }^{33}$ Nevertheless, to our best knowledge, the interaction of ND-loaded nanofibers with cells and their potential use in bone tissue engineering has not yet been investigated.

In the present study, we therefore constructed nanofibrous membranes by electrospinning PLGA mixed with ND particles as potential growth supports for bone cells. We investigated the adhesion, proliferation, and viability of human osteoblast-like MG-63 cells in cultures on these materials. We expected an additional nanostructure to be created on the fiber surface by the incorporated ND, and thus further 
enhancement of the scaffold bioactivity. We also anticipated enhanced mechanical properties of PLGA membranes reinforced with ND. The mechanical properties of the membranes were assessed using rupture tests ${ }^{34}$ and tensile strength measurements. ${ }^{35-37}$ Finally, we expected no significant inflammatory activation of cells on these scaffolds. Potential immune activation of cells was estimated by their secretion of tumor necrosis factor alpha (TNF- $\alpha$ ) into the cell culture medium, and by the concentration of intercellular adhesion molecule-1 (ICAM-1) in cell homogenates. For these immunological tests, mouse macrophage-like RAW 264.7 cells were also used.

\section{Materials and methods Preparation of nanofibrous membranes}

The experiments were carried out on nanofibrous membranes made of a copolymer of L-lactide and glycolide (ratio 85:15) Purasorb PLG 8531 (Purac Biomaterials, Frankfurt, Germany). The polymer was dissolved in a mixture of methylene chloride (Sigma-Aldrich, St Louis, MO) and dimethyl formamide (Sigma) at a concentration of $2.3 \mathrm{wt} \%$. The ratio of the two solvents was 2:3. The nanofibrous membranes were then prepared by electrospinning in a Nanospider ${ }^{\mathrm{TM}}$ machine (Elmarco, Liberec, Czech Republic) using a vertically positioned spike-like electrode on which the polymer solution was applied with a micropipette. The electrospinning conditions were optimized prior to membrane fabrication, resulting in an applied voltage of $24.6 \mathrm{kV}$ and a working distance between the electrodes of $145 \mathrm{~mm}$, ie, an electric field strength of $1.79 \mathrm{kV} / \mathrm{cm}$. The polymer solution was positioned between the two electrodes in the electrospinning setup, and when a high voltage was applied, the electric field overcame viscoelastic forces of the polymer solution and nanofibers were formed.

A polypropylene fabric, placed above the electrode, was used as a carrier substrate for collecting the nanofibers, which were stacked to several layers by repeated deposition of the PLGA solution on the same region of the substrate (a circular region approximately $10 \mathrm{~cm}$ in diameter). Four milliliters of the solution was used for preparing a membrane to cover this region, and this solution was applied to the top of the electrode 80 times in a quantity of $50 \mu \mathrm{L}$ for each application.

Some nanofibrous PLGA membranes were created in combination with diamond nanoparticles. ${ }^{38-41} \mathrm{In} 1 \mathrm{~mL}$ of PLGA solution, $0.007 \mathrm{~g}$ of the ND powder was added and was homogeneously dispersed by mixing and sonication (Labsonic U-2000, B Braun Biotech, Goettingen, Germany, sonication time 5 seconds). The sonication was performed immediately before electrospinning in order to minimize clustering of diamond nanoparticles. The concentration of ND in PLGA diluted in methylene chloride and dimethyl formamide was therefore $0.7 \mathrm{wt} \%$, and in the pure PLGA after evaporation of the solvents, the concentration was calculated to be almost $23 \mathrm{wt} \%$.

\section{Characterization of physicochemical properties of nanofibrous membranes}

The morphology of the membranes was evaluated by scanning electron microscopy using an XL30CP device, Phillips Electron Optics GmbH, Kassel, Germany, after gold sputtering on an SCD 500 device (CAL-Tec, Ashford, UK). The following parameters were measured on scanning electron microscopy images, using Atlas Software (Tescan Ltd, Brno, Czech Republic):

- Diameter of nanofibers

- Size of pores between nanofibers; areas of void spaces among the fibers were measured on scanning electron microscopy images ${ }^{23}$

- Size of material clusters were measured by the area of these clusters projected on the material surface

- Density of material clusters was calculated per $\mathrm{mm}^{2}$ of the membrane.

The distribution of diamond nanoparticles within the PLGA nanofibers was evaluated by transmission electron microscopy. The transmission electron microscopic images were recorded on a Philips CM120 microscope with an $\mathrm{LaB}_{6}$ cathode operated at $120 \mathrm{kV}$, equipped with an SIS Veleta CCD camera. A small piece of nanofibrous membrane was placed between two carbon-coated copper grids to fix the membrane in the sample holder. Single nanofibers were observed at the edges of the membrane.

The wettability of the membranes was measured by a static method in a material-water droplet system using a reflection goniometer (Surface Energy Evaluation System, Masaryk University, Brno, Czech Republic). ${ }^{28}$

The mechanical properties of PLGA membranes with and without ND were evaluated by rupture tests in a texture analyzer (TA500, Lloyd Instruments, Fareham, UK) using an Instron probe method according to a protocol adapted from that of dos Santos et al. ${ }^{34}$ Briefly, the membranes were clamped in a CellCrown (Scaffdex Oy, Tampere, Finland) of $10 \mathrm{~mm}$ diameter and $1 \mathrm{~cm}$ height. The thickness of the membranes was 20 microns, as measured by a caliper ${ }^{7}$ (manual micrometer with limits $0-25 \mathrm{~mm}$ and with a precision of $0.01 \mathrm{~mm}$; NSK, Tochigi, Japan). The resistance to deformation induced by a $3 \mathrm{~mm}$ diameter cylindrical probe 
was studied. The probe penetrates and deforms the membrane causing the creation of an additional vertical force, which is measured. The maximal load and deflection is a measure of the maximum force and deformation that the membranes can undergo before permanent deformation occurs. Rupture of the fibers is considered to occur when the force drops to $50 \%$ or less of the maximum load. This parameter together with the deflection at rupture gives an indication of the resistance of the fibers to this kind of deformation.

For measurements of tensile strength, the PLGA and PLGA-ND membranes were cut into rectangular strips $40 \mathrm{~mm}$ in length and $21-25 \mathrm{~mm}$ in width. The reason for these variations in the width was raveling of the edges (margins) of the samples. The specific weight of these samples was $3.1( \pm 5 \%) \mathrm{g} / \mathrm{m}^{2}$, as calculated from their total weight (determined with accuracy of $0.0005 \mathrm{~g}$ ), and their dimensions. For each material type, six samples were prepared. The shorter sides (ends) of the tested samples were strengthened by a paper tape in order to prevent damage of the nanofibrous membranes during their preparation for the tensile test, particularly during their mounting in the gripping units of the testing machine. The LabTes4.100 SP1 machine was used, and set up to the maximal range of $50 \mathrm{~N}$, with precision lower than $0.1 \%$ for a force of $2 \mathrm{~N}$. The samples were loaded with a constant force until failure. The force needed for tearing the membranes (ie, maximum tensile force; also referred to as ultimate tensile strength) $)^{35,37}$ was determined from the software of the testing machine.

The molecular structure of PLGA and PLGA-ND membranes was examined using attenuated total reflectance Fourier-transform infrared (FT-IR) spectroscopy. Transmittance spectra were acquired using a Biorad FT-IR spectrometer FTS 575C equipped with a "Golden Gate" attenuated total reflectance accessory. The latter was fitted with a diamond crystal. The spectra were recorded over the range $4000-500 \mathrm{~cm}^{-1}$.

\section{Cell culture on the nanofibrous membranes}

The nanofibrous membranes were detached from the underlying polypropylene substrate, cut into square samples $(1 \times 1 \mathrm{~cm})$, fixed in CellCrown inserts (Scaffdex; Figure 1A and $\mathrm{B}$ ), and sterilized by gamma irradiation (dose $25 \mathrm{kGy}$, in accordance with the ISO 11137 standard).

The CellCrown inserts with membrane samples were inserted into polystyrene 24-well cell culture plates (TPP Techno Plastic Products, Trasadingen, Switzerland; well diameter $1.5 \mathrm{~cm}$; Figure 1B), and the membranes were rinsed overnight with Dulbecco's Modified Eagle Minimum Essential Medium (Sigma). The samples were then seeded with human osteoblast-like MG-63 cells (European Collection of Cell Cultures, Salisbury, UK). Each well contained 30,000 cells (approximately 17,000 cells $/ \mathrm{cm}^{2}$ ) and $1.5 \mathrm{~mL}$ of the Dulbecco's Modified Eagle Minimum Essential Medium supplemented with 10\% fetal bovine serum (Gibco, Paisley, UK) and gentamicin (40 $\mu \mathrm{g} / \mathrm{mL}, \mathrm{LEK}, \mathrm{Ljubljana,} \mathrm{Slovenia).}$ Cells were cultured for one, 3 , or 7 days at $37^{\circ} \mathrm{C}$ in a humidified atmosphere of $5 \%$ of $\mathrm{CO}_{2}$ in the air. The polystyrene culture well was used as a reference material. Four samples were used for each experimental group and time interval, and the experiment described below was repeated three times.

\section{Evaluation of adhesion and growth of bone cells on nanofibrous membranes}

On days 1, 3 and 7 after seeding, the samples were rinsed in phosphate-buffered saline. The cells on one sample per experimental group and time interval were fixed by $70 \%$ cold ethanol $\left(-20^{\circ} \mathrm{C}\right)$ and stained with a combination of Texas Red $\mathrm{C}_{2}$-maleimide fluorescent membrane dye (Molecular Probes, Invitrogen, Paisley, UK; concentration $20 \mathrm{ng} / \mathrm{mL}$ in phosphate-buffered saline) and Hoechst 33342 nuclear dye (Sigma, $5 \mu \mathrm{g} / \mathrm{mL}$ in phosphate-buffered saline). The morphology and distribution of cells on the membrane surface were then evaluated in pictures taken under the Nikon Eclipse Ti-E microscope equipped with a Nikon DS-Qi1 MC digital camera and NIS-Elements AR software, version 3.10.

On day 1 after seeding, the size of cell spreading area, ie, the area projected on the material, was also measured, using Atlas Software (Tescan). The cells that developed intercellular contacts were excluded from the evaluation. On each sample, 60-93 cells were evaluated.

The three remaining samples were used for evaluating the cell number. The cells were rinsed with phosphate-buffered saline, released with trypsin-EDTA solution (Sigma; incubation 5 minutes at $37^{\circ} \mathrm{C}$ ) and counted in a Bürker hemocytometer under an Olympus IX 51 microscope. For each sample, eight cell number measurements were performed. The cell numbers obtained on days 1, 3 and 7 after seeding were used for constructing growth curves and for calculating the cell population doubling time, using the following equation:

$$
D T=\log 2 \frac{t-t_{0}}{\log N_{t}-\log N_{t_{0}}}
$$

where $t_{0}$ and $t$ represent earlier and later time intervals after seeding, respectively, and $N_{t_{0}}$ and $N_{t}$ represent the number of cells at these intervals..$^{28,42}$ 

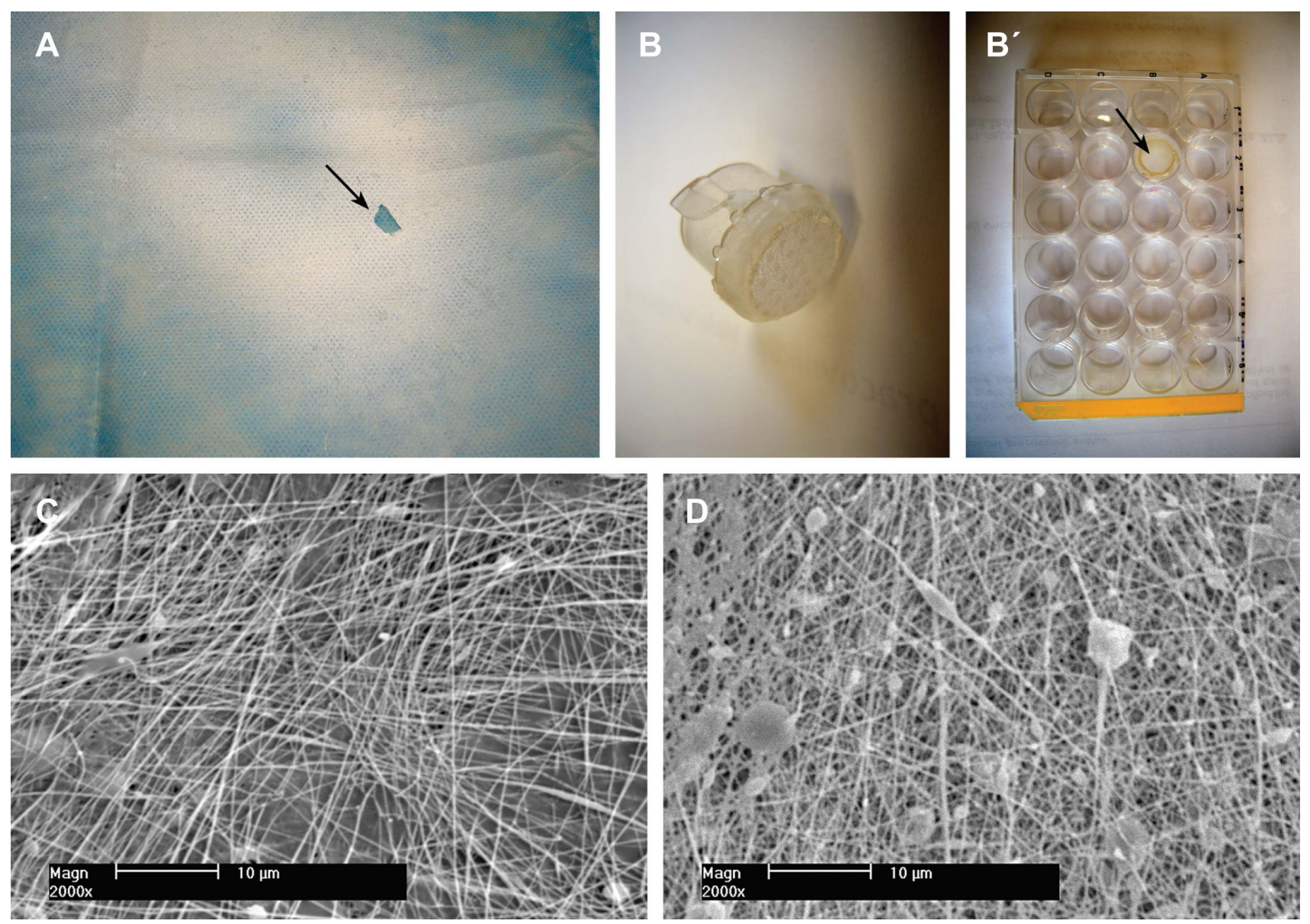

Figure I Morphology of nanofibrous PLGA scaffolds enriched with nanodiamond. (A) Gross morphology of a composite PLGA-nanodiamond membrane deposited on polypropylene fabric. An arrow indicates a site where a part of the membrane was detached. (B) A composite PLGA-nanodiamond membrane fixed with a Scaffdex CellCrown insert. (B', Scaffdex CellCrown insert with a PLGA-nanodiamond membrane in a 24-well plate, arrow). (C) Pure PLGA nanofibrous membrane. (D) Composite PLGA-nanodiamond membrane. (A and B) Nikon Coolpix S620 digital camera and (C and D) XL30CP scanning electron microscope (Phillips Elektron Optics GmbH, Kassel, Germany), objective magnification 2000x, bar $10 \mu \mathrm{m}$.

Abbreviation: PLGA, copolymer of L-lactide and glycolide.

\section{Evaluation of cell viability}

On days 1,3 and 7 after seeding, the cells were rinsed with phosphate-buffered saline, and their viability was determined by the LIVE/DEAD viability/cytotoxicity kit for mammalian cells (Molecular Probes) according to the manufacturer's protocol. Briefly, the cells were incubated for 5-10 minutes at room temperature in a mixture of two of the following probes: calcein AM, a marker of esterase activity in living cells, emitting green fluorescence, and ethidium homodimer-1, which penetrates into dead cells through their damaged membrane and produces red fluorescence. Live and dead cells were then counted in microphotographs taken under an epifluorescence microscope (Olympus IX-51, DP-70 digital camera, Japan). For each experimental group and time interval, two samples were used, and on each sample the cells were evaluated in 10 microphotographs.

\section{Immunofluorescence staining of molecules participating in cell-matrix adhesion and cell spreading}

On day 3 after seeding, the presence and spatial arrangement of the following molecules in MG-63 cells were evaluated: talin, an integrin-associated protein present in focal adhesion plaques, also reported as a protein of the "cell membrane cytoskeleton" and known to participate in cell-substrate adhesion; vinculin, another protein of focal adhesion plaques, participating in cell-substrate adhesion and stabilizing the focal adhesions; ${ }^{43}$ beta-actin, an important component of the cell cytoplasmic cytoskeleton, associated with focal adhesion plaques.

For immunofluorescence staining of these molecules, the cells on day 3 after seeding were rinsed twice in phosphatebuffered saline and fixed with $70 \%$ ethanol $\left(-20^{\circ} \mathrm{C}\right.$, 20 minutes) pretreated with $1 \%$ bovine serum albumin in 
phosphate-buffered saline containing $0.05 \%$ Triton X-100 (Sigma) for 20 minutes at room temperature in order to block nonspecific binding sites and to permeabilize the cell membrane. The cells were then incubated with the following primary mouse monoclonal antibodies: anti-chicken talin (Sigma, clone 8D4) anti-human vinculin (Sigma) and antisynthetic N-terminal peptide of $\beta$-actin (Sigma). All antibodies were diluted in phosphate-buffered saline to concentrations of 1:200 and applied overnight at $4{ }^{\circ} \mathrm{C}$. After rinsing with phosphate-buffered saline, the secondary antibody, represented by goat anti-mouse $\mathrm{F}\left(\mathrm{ab}^{\prime}\right) 2$ fragment of IgG conjugated with Alexa Fluor ${ }^{\circledR} 488$ (dilution 1:1000; Molecular Probes) was added for 1 hour at room temperature and incubated in the dark. The cells were then rinsed in phosphatebuffered saline, mounted under microscopic glass coverslips in a Gel/Mount permanent fluorescence-preserving aqueous mounting medium (Biomeda Corporation, Foster City, CA) and evaluated under a Leica confocal laser scanning microscope (TCS SP2, Germany).

\section{Potential immune activation of cells on nanofibrous membranes}

The secretion of TNF- $\alpha$ into the cell culture medium and the concentration of ICAM-1 in cell homogenates were measured in human osteoblast-like MG-63 cells and murine macrophage-like RAW 264.7 cells (American Type Culture Collection, Manassas, VA). The cells were seeded on PLGA or PLGA-ND membranes fixed in CellCrown inserts in polystyrene 24-well cell culture plates (TPP; well diameter $1.5 \mathrm{~cm}$ ). Each well contained 30,000 cells and $1.5 \mathrm{~mL}$ of the culture medium. MG-63 cells were cultured in the Dulbecco's Modified Eagle Minimum Essential Medium mentioned above, and for RAW 264.7, RPMI-1640 medium (Sigma; 10\% fetal bovine serum, $40 \mu \mathrm{g} / \mathrm{mL}$ gentamicin) was used.

As reference samples, pure polystyrene wells and wells with CellCrown inserts were used. For comparison, PLGA meshes with hydroxyapatite (HAp) nanoparticles (Sigma; $<200 \mathrm{~nm}$ particle size) were used. The concentration of HAp in PLGA was similar as in the case of ND (ie, approximately $23 \mathrm{wt} \%$ ).

After 24 hours, the membranes were transferred into fresh wells filled with cell culture medium in order to exclude the cells adhering on the underlying well bottom from the evaluation. In the reference wells with and without CellCrown inserts, the culture medium was also changed. The cells were then cultivated for an additional 6 days. For each material and cell type, four samples were used.
After 6 days of cultivation, the cell culture medium was collected and used for measuring the concentration of TNF- $\alpha$ by a sandwich enzyme-linked immunosorbent assay (ELISA) using commercially available kits. A human TNF- $\alpha$ Quantikine ELISA kit and mouse TNF- $\alpha$ Quantikine ELISA kit were used for the MG-63 and RAW 264.7 cells, respectively. Both kits were purchased from R and D Systems (Minneapolis, MN) and used according to the manufacturer's protocol.

As a positive control for TNF- $\alpha$ production, MG-63 or RAW 264.7 cells grown in polystyrene culture wells and stimulated with lipopolysaccharide (LPS) from Escherichia coli (0111:B4, $\gamma$-irradiated, BioXtra, Sigma) were used. Lipopolysaccharide was applied in concentrations ranging from 0 to $10 \mu \mathrm{g} / \mathrm{mL}$ on day 6 after seeding for 24 hours. For each concentration, four wells were used. As a negative control, fresh Dulbecco's Modified Eagle Minimum Essential Medium or RPMI-1640 media supplemented with fetal bovine serum and gentamicin, which were not exposed to cells, were used.

The concentrations of TNF- $\alpha$ in cell culture media were determined from calibration curves and given in pg per 100,000 cells, ie, not per $\mathrm{mL}$ of the culture media, as usual. ${ }^{44,45}$ The reason was that the cell numbers on the tested materials were different. For MG-63 cells, it ranged on average from 305,600 to 753,900 cells/sample, and for RAW 264.7 cells, from 748,900 to $1,220,600$ cells/sample (Figure 9A and B).

For measuring the concentration of ICAM- 1 by ELISA in cell homogenates (per mg of protein), the MG-63 cells were then harvested by trypsin-EDTA solution in phosphate-buffered saline (Sigma) and RAW 264.7 cells by $0.05 \%$ EDTA in phosphate-buffered saline and counted in a Bürker hemocytometer. The cells $\left(10^{6}\right.$ cells $\left./ \mathrm{mL}\right)$, resuspended in distilled and deionized water, were kept in a freezer at $-70^{\circ} \mathrm{C}$ overnight. The cells were then homogenized by ultrasonication for 40 seconds in a sonicator (UP 100 H, Dr Hielscher GmbH; cycle 1, amplitude 70\%), and the protein content was measured using a Coomassie Plus (Bradford) Kit (Cat. No. 23236, Thermo Fisher Scientific Inc., Rockford, IL USA).

Aliquots of the cell homogenates corresponding to $1-50 \mu \mathrm{g}$ of protein in $50 \mu \mathrm{L}$ of water were adsorbed on 96-well microtiter plates (Nunc-Immuno ${ }^{\mathrm{TM}}$ Plates, F96 MaxiSorp, Cat. No. 442404, Nunc a/s, Roskilde, Denmark) at $4^{\circ} \mathrm{C}$ overnight. After washing twice with phosphatebuffered saline (100 $\mu \mathrm{L} /$ well), the nonspecific binding sites were blocked by $0.02 \%$ gelatin in phosphate-buffered saline (100 $\mu \mathrm{L} /$ well, 60 minutes). As primary antibodies, 
monoclonal mouse antihuman ICAM-1 antibody was used in MG-63 cells (Exbio, Prague, Czech Republic) and monoclonal rat anti-mouse ICAM-1 antibody (Exbio Prague, clone YN1/1.7.4). The antibodies were diluted in phosphate-buffered saline and applied for 60 minutes at room temperature $\left(50 \mu \mathrm{L} /\right.$ well). Goat anti-mouse $\mathrm{F}\left(\mathrm{ab}{ }^{\prime}\right)_{2}$ IgG fragment (Sigma, dilution 1:1000) was used after the mouse primary antibody, and goat anti-rat IgG (BioLegend, dilution 1:1000) was used after the rat primary antibody as secondary antibodies. Both secondary antibodies were conjugated with peroxidase and applied for 45 minutes (100 $\mu \mathrm{L} /$ well). This step was followed by double washing in phosphate-buffered saline and orthophenylendiamine reaction (Sigma, concentration $2.76 \mathrm{mM}$ ) using $0.05 \% \mathrm{H}_{2} \mathrm{O}_{2}$ in $0.1 \mathrm{M}$ phosphate buffer (pg 6.0, dark place, $100 \mu \mathrm{L} /$ well). The reaction was stopped after 10-30 minutes by $2 \mathrm{M}$ $\mathrm{H}_{2} \mathrm{SO}_{4}(50 \mu \mathrm{L} /$ well $)$, and the absorbance was measured at $490 \mathrm{~nm}$ and $690 \mathrm{~nm}$ using a Versa Max microplate reader (Molecular Devices Corporation, Sunnyvale, CA). The absorbances obtained from cells growing on PLGA and PLGA-ND membranes were expressed as a percentage of the values obtained in the control cultures on standard polystyrene wells.

\section{Statistics}

The quantitative results were presented as the mean \pm standard error of mean. Statistical significance was evaluated using analysis of variance, Student-Newman-Keuls method, or the two-tailed $t$-test. Values of $P \leq 0.05$ were considered as significant.

Table I Morphological parameters of pure poly(lactide-coglycolide) (PLGA) membranes and PLGA membranes with nanodiamond (PLGA-ND)

\begin{tabular}{lll}
\hline Parameters & PLGA & PLGA-ND \\
\hline $\begin{array}{ll}\text { Fibers } \\
\text { Diameter, range }\end{array}$ & $124-35 \mathrm{Inm}$ & $124-877 \mathrm{~nm}$ \\
$\begin{array}{l}\text { Diameter, mean } \pm \mathrm{SEM} \\
\text { Clusters }\end{array}$ & $218 \pm 4 \mathrm{~nm}$ & $270 \pm 9 \mathrm{~nm}^{*}$ \\
Area, range & & \\
Area, mean $\pm \mathrm{SEM}$ & $0.20-10.68 \mu \mathrm{m}^{2}$ & 0.31 to $24.10 \mu \mathrm{m}^{2}$ \\
$\begin{array}{l}\text { Density, mean } \pm \mathrm{SEM} \\
\text { Pores }\end{array}$ & $2.13 \pm 0.75 \mu \mathrm{m}^{2}$ & $3.54 \pm 0.90 \mu \mathrm{m}^{2}$ \\
Area, range & $8,340 \pm 1,495 / \mathrm{mm}^{2}$ & $33,361 \pm 6,182 / \mathrm{mm}^{2}$ \\
Area, mean \pm SEM & $0.10-6.95 \mu \mathrm{m}^{2}$ & $0.10-1.50 \mu \mathrm{m}^{2}$ \\
\hline
\end{tabular}

Notes: Mean \pm SEM. from 129-193 measurements (fibers), 13-43 measurements (cluster area), four measurements (cluster density), and 181-192 measurements (pores). ANOVA, Student-Newman-Keuls method; statistical significance: $* P \leq 0.05$ in comparison with PLGA.

Abbreviations: ANOVA, analysis of variance; SEM, standard error of the mean.

\section{Results}

\section{Properties of nanofibrous membranes}

Both pure PLGA and composite PLGA-ND membranes formed a fine cobweb-like layer on blue polypropylene fabrics, which served as a carrier for the nanofibrous membranes. The pure PLGA membrane was white, whereas the membrane with ND was grayish. As revealed by scanning electron microscopy, both membranes were composed of mostly straight and randomly oriented fibers. These fibers were thicker and the pores between them were smaller in the composite PLGA-ND membranes. The PLGA-ND membranes also contained more material clusters. Their density, calculated per $\mathrm{mm}^{2}$ projected on the membrane, was approximately four times higher than in pure PLGA membranes, and these clusters were on an average larger than those in PLGA membranes, although this difference was not statistically significant due to the great variation in cluster size (Figure 1, Table 1).

Transmission electron microscopy images of PLGA-ND fibers are shown in Figure 2. The images clearly show that the diamond nanoparticles form predominantly small clusters embedded in the PLGA matrix. The size of the clusters is variable, ranging from a few particles to large clusters spanning the whole width of the fibers, ie, in some cases up to $200 \mathrm{~nm}$. The nanofibers exhibit great variability in thickness, from very thin threads less than $5 \mathrm{~nm}$ in diameter to thick fibers approaching $200 \mathrm{~nm}$ in diameter. The diamond nanoparticles also occurred in the form of isolated clusters attached to the surface of the PLGA nanofibers.

As revealed by reflection goniometry, the static water drop contact angle for both types of nanofibrous membranes was about $70^{\circ}$.

The rupture tests showed that membranes consisting of PLGA-ND resisted a load of $1.29 \pm 0.22 \mathrm{~N}$ until rupture, significantly more than pure PLGA fiber membranes, which withstood $0.75 \pm 0.19 \mathrm{~N}$ (Figure 3A). As indicated by Figure $3 \mathrm{~B}$, the deflection of the rupture probe at failure was $1.21 \pm 0.08 \mathrm{~mm}$ and $0.97 \pm 0.06 \mathrm{~mm}$ in the case of PLGA-ND membranes and PLGA membranes, respectively. This difference was also significant according to a two-tailed t-test ( $P<0.001, \mathrm{n}=10$ in both groups). However, as indicated by the tensile strength measurements, the force needed for tearing both PLGA and PLGA-ND membranes was similar, ie, approximately $0.074( \pm 10 \%) \mathrm{N} / \mathrm{mm}$ (Table 2$)$.

With regard to the FTIR analysis, Zhao et $\mathrm{al}^{46}$ demonstrated ND-PLA interactions by shifts in characteristic polymer bands in the FTIR spectra corresponding to the $\mathrm{C}=\mathrm{O}$ stretch and bending of $-\mathrm{OH}$ bonds in $-\mathrm{CH}\left(\mathrm{CH}_{3}\right)-\mathrm{OH}$ end groups. As can be seen by comparing the FTIR spectra of 

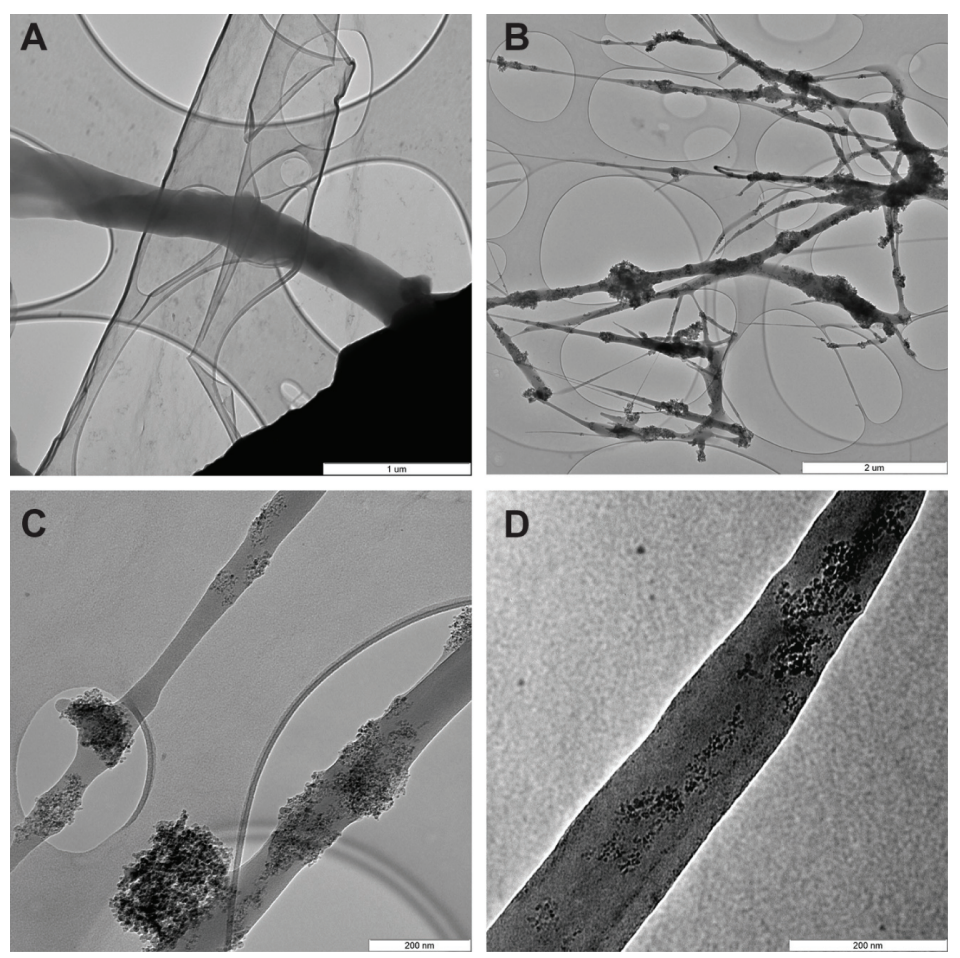

Figure 2 Transmission electron microscopy images of pure PLGA fibers (A) and PLGA fibers with diamond nanoparticles (B-D). (B) Network of PLGA with diamond nanoparticles, showing variations in fiber thickness and size of the material clusters. (C) Individual fibers with clusters of diamond nanoparticles. (D) Diamond nanoparticles relatively homogeneously distributed in a PLGA fiber.

Notes: The layers with elliptical openings (A-C) are amorphous carbon membranes of the grid used to fix the sample. A Philips CMI20 transmission electron microscope, LaB6 cathode operated at $120 \mathrm{kV}$, and SIS Veleta CCD camera, were used. Scale bar I $\mu \mathrm{m}(\mathbf{A}), 2 \mu \mathrm{m}$ (B), and $200 \mathrm{~nm}$ (C and D).

Abbreviation: PLGA, copolymer of L-lactide and glycolide.

PLGA and PLGA-ND in Figure 4, only very small differences were seen in characteristic PLGA peaks, ie, $\mathrm{C}=\mathrm{O}$ stretch at $1748 \mathrm{~cm}^{-1},-\mathrm{OH}$ bending in $-\mathrm{CH}\left(\mathrm{CH}_{3}\right)-\mathrm{OH}$ end groups at $1043 \mathrm{~cm}^{-1}$, and asymmetrical $\mathrm{C}-\mathrm{O}-\mathrm{C}$ stretch at $1083 \mathrm{~cm}^{-1} \cdot 46,47$

A

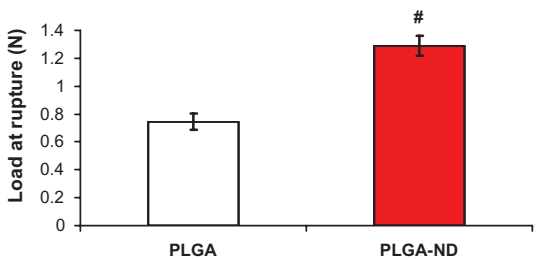

B

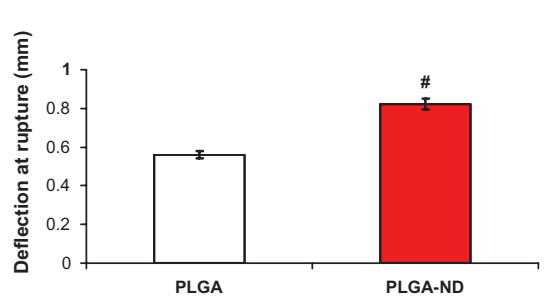

Figure 3 Load at rupture (A) and deflection of probe at rupture (B) of nanofiber membranes consisting of pure PLGA and PLGA-ND.

Notes: The mean \pm standard error of the mean are presented for 10 samples from each experimental group. Two-tailed $t$-test, $P \leq 0.00 \mathrm{I}$ in comparison with PLGA. Abbreviations: PLGA, copolymer of L-lactide and glycolide; ND, nanodiamond.

\section{Adhesion and growth of MG-63 cells on nanofibrous scaffolds}

The initial adhesion and subsequent growth of MG-63 cells was similar on both pure and ND-loaded PLGA membranes. On the first day after seeding, the number of initially adhering cells on the pure PLGA membranes was $11,300 \pm 1200 \mathrm{cells} / \mathrm{cm}^{2}$, and on the PLGA-ND membranes, the number was $10,951 \pm 1027 \mathrm{cells} / \mathrm{cm}^{2}$. The highest average number of initially adhered cells was observed on the control polystyrene dishes $\left(14,000 \pm 1038 \mathrm{cells} / \mathrm{cm}^{2}\right)$. However, as revealed by analysis of variance, this value was not statistically different from the values obtained on the two nanofibrous membranes (Figure 5A). On the other hand, the cells on polystyrene dishes adhered by a significantly larger cell spreading area $\left(1057 \pm 33 \mu \mathrm{m}^{2}\right)$ than the cells on both pure and ND-loaded PLGA membranes $\left(442 \pm 15 \mu \mathrm{m}^{2}\right.$ and $477 \pm 16 \mu \mathrm{m}^{2}$, respectively, Figure 5B).

From day 1 to 3 after seeding (ie, in an early phase of exponential cell growth) the cells on both PLGA and PLGA-ND membranes proliferated more slowly, ie, with longer cell population doubling times than the cells on 
Table 2 Tensile strength of poly(lactide-co-glycolide) (PLGA) and PLGA membranes with nanodiamond (PLGA-ND) membranes

\begin{tabular}{|c|c|c|c|c|c|c|}
\hline \multirow{2}{*}{$\begin{array}{l}\text { Sample } \\
\mathbf{N}\end{array}$} & \multicolumn{3}{|l|}{ PLGA } & \multicolumn{3}{|l|}{ PLGA-ND } \\
\hline & Force $(\mathbf{N})$ & Width (mm) & $\begin{array}{l}\text { Resultant force } \\
(\mathrm{N} / \mathrm{mm})\end{array}$ & Force $(\mathbf{N})$ & Width (mm) & $\begin{array}{l}\text { Resultant force } \\
(\mathrm{N} / \mathrm{mm})\end{array}$ \\
\hline 1 & 1.651 & 24.03 & 0.0687 & 1.655 & 23.24 & 0.0712 \\
\hline 2 & 1.809 & 23.65 & 0.0765 & 1.954 & 24.46 & 0.0799 \\
\hline 3 & 1.997 & 26.80 & 0.0745 & 1.867 & 25.75 & 0.0725 \\
\hline 4 & 1.725 & 23.47 & 0.0735 & 1.877 & 23.43 & $0.080 \mathrm{I}$ \\
\hline 5 & 1.579 & 21.84 & 0.0723 & 1.773 & 24.73 & 0.0717 \\
\hline 6 & $1.75 \mathrm{I}$ & 21.62 & 0.0810 & 1.648 & 23.88 & 0.0690 \\
\hline Mean \pm SEM & $1.7520 \pm 0.0589$ & $23.5683 \pm 0.7628$ & $0.0744 \pm 0.0017$ & $1.7957 \pm 0.0513$ & $24.2483 \pm 0.3810$ & $0.0741 \pm 0.0019$ \\
\hline
\end{tabular}

Note: Mean \pm SEM from six samples for each experimental group.

Abbreviations: ANOVA, analysis of variance; SEM, standard error of the mean.

polystyrene dishes (Table 3, Figure 5C). As a result, on day 3 after seeding, the cells on both PLGA and PLGA-ND scaffolds reached significantly lower cell population densities $\left(36,100 \pm 2200 \mathrm{cells} / \mathrm{cm}^{2}\right.$ and $37,000 \pm 2500 \mathrm{cells} / \mathrm{cm}^{2}$, respectively) than on polystyrene dishes $(61,900 \pm$ 2100 cells $/ \mathrm{cm}^{2}$ ). At the same time, the cell population densities on both nanofibrous scaffolds were similar (Figure 5A and C).

From day 3 to 7 after seeding (ie, in a late phase of exponential cell growth), the cell proliferation became quicker on both types of nanofibrous membranes than on polystyrene, ie, these cells proliferated with shorter cell population doubling times (Table 3 ). In spite of this, on day 7 after seeding, the cell population densities still remained lower on pure and ND-loaded PLGA membranes $\left(167,700 \pm 4500 \mathrm{cells} / \mathrm{cm}^{2}\right.$ and $169,900 \pm 6100 \mathrm{cells} / \mathrm{cm}^{2}$, respectively) than on polystyrene dishes $(220,500 \pm$ 6300 cells $/ \mathrm{cm}^{2}$ ).

Nevertheless, the cells on PLGA with ND were similar in shape to the cells on PLGA and polystyrene dishes,

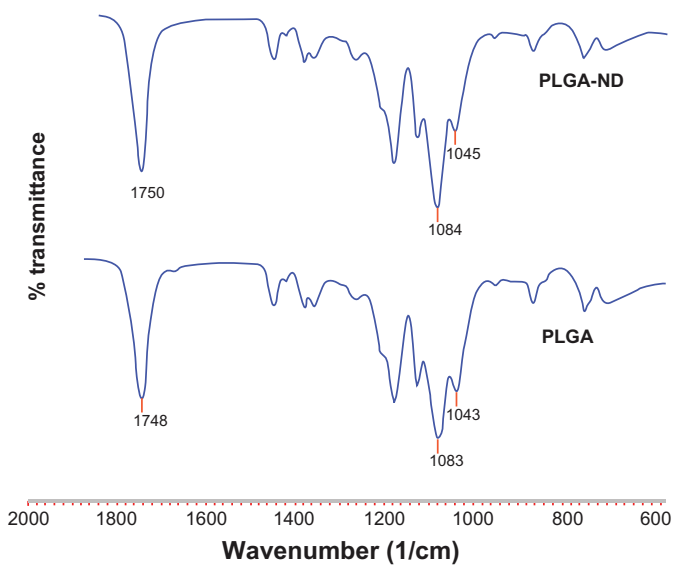

Figure 4 Fourier transform infrared spectra of nanofiber membranes consisting of pure PLGA and PLGA-ND.

Abbreviations: PLGA, copolymer of L-lactide and glycolide; ND, nanodiamond. ie, polygonal or spindle-like. They were distributed homogeneously on the samples, their number rose continuously during the testing period, and at the end of the testing period, these cells were able to form a confluent layer (Figures 6 and 7). From this point of view, the MG-63 cells on PLGA-ND membranes behaved physiologically without noticeable signs of cell damage.

\section{Viability of MG-63 cells} on nanofibrous scaffolds

Staining the cells with the LIVE/DEAD viability/cytotoxicity kit showed that the percentage of living cells on all tested materials was relatively high, ranging from $92 \%$ to $99 \%$ (Figures 5D and 7). The lowest values (92\%-94\%) were obtained in cells on composite PLGA-ND membranes. These values were significantly lower than those obtained in cells on the control polystyrene dishes, and on days 3 and 7 were also significantly lower than the values on the pure PLGA membranes. Also, on pure PLGA membranes, cell viability was lower than that on the polystyrene dishes, except on day 7 , when the two values were similar.

On the corresponding substrates, the cell viability was similar on day 1 and day 3 after seeding. However, from day 3 , the viability showed a tendency to decrease, which was most pronounced on polystyrene dishes. On these substrates, the cell viability on day 7 was significantly lower than on day 1 and day 3. On PLGA-ND scaffolds, the cell viability on day 7 was lower than on day 3 (Figure 5D).

\section{Focal adhesion plaques and actin cytoskeleton in MG-63 cells on nanofibrous scaffolds}

Immunofluorescence staining showed that in cells on both types of nanofibrous membranes and the control microscopic 
A

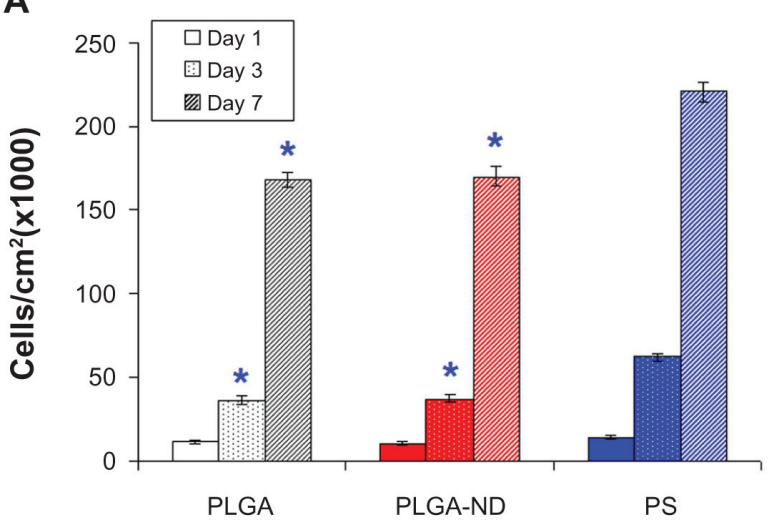

C

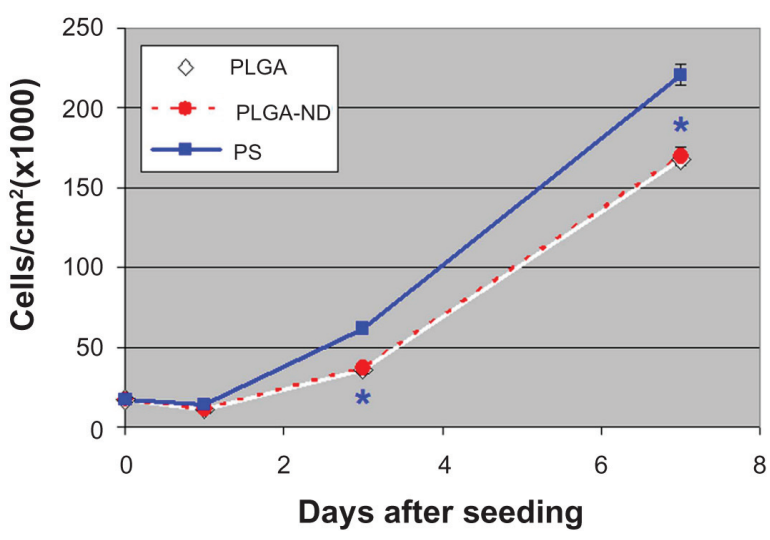

B

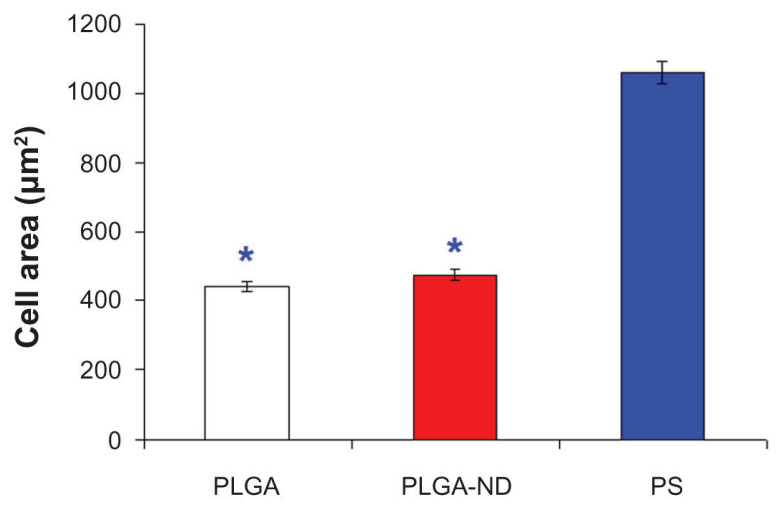

D

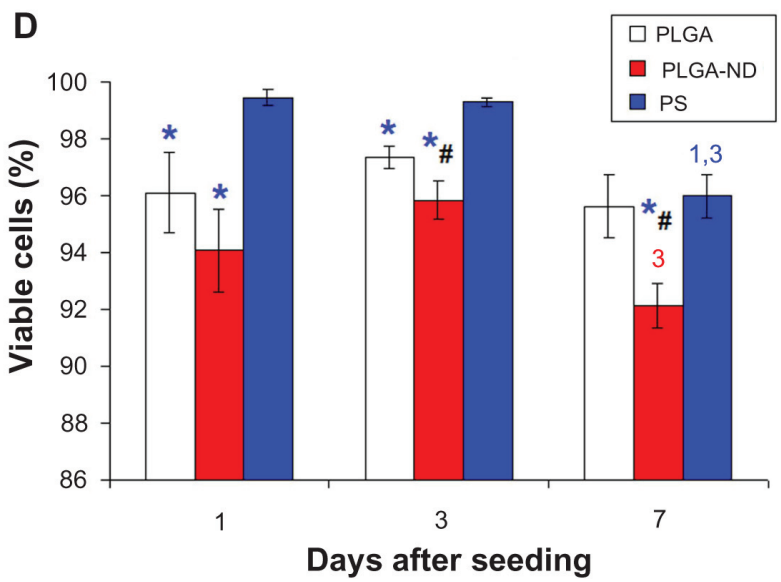

Figure 5 (A) Number of human osteoblast-like MG-63 cells on days I, 3, and 7 after seeding on a pure nanofibrous PLGA membrane, a PLGA-ND membrane, and bottom of polystyrene culture wells. (B) Size of cell spreading area on day I after seeding. (C) Growth dynamics of cells on substrates from days I-7. (D) Viability of MG-63 cells on days I, 3 and 7 after seeding on the substrates. Mean \pm standard error of the mean of three experiments. In total, 72 measurements of cell numbers (A, C) and 20 measurements of cell viability (D) were performed, and 200-278 cell spreading areas (B) were evaluated for each experimental group and time interval.

Notes: Analysis of variance, Student-Newman-Keuls method. ${ }^{*}, P \leq 0.05$ in comparison with polystyrene and PLGA, respectively. ${ }^{1,3} P \leq 0.05$ in comparison with cells on days I and 3 after seeding on corresponding substrate.

Abbreviations: PLGA, copolymer of L-lactide and glycolide; ND, nanodiamond; PS, polystyrene.

glass coverslips, talin either was distributed diffusely throughout all the cells or was organized into focal adhesion plaques. These plaques were more apparent in cells on glass and PLGA membranes with ND than in cells on the pure PLGA scaffolds. On both nanofibrous scaffolds, the focal

Table 3 Cell population doubling time (DT) of MG 63 cells on poly(lactide-co-glycolide) (PLGA) membranes with and without nanodiamond (ND), and tissue culture polystyrene dishes (PS) as a reference material

\begin{tabular}{llll}
\hline Material/DT & PLGA & PLGA-ND & PS \\
\hline $\mathrm{DT}_{1-3}$ (hours) & $32.5 \pm 3.2^{*}$ & $27.5 \pm 1.3$ & $22.5 \pm 0.6$ \\
$\mathrm{DT}_{3-7}$ (hours) & $43.6 \pm 1.7^{*}$ & $45.6 \pm 2.0^{*}$ & $52.8 \pm 1.2$ \\
$\mathrm{DT}_{1-7}$ (hours) & $37 \pm 0.5$ & $36.8 \pm 1.1$ & $36.2 \pm 0.6$ \\
\hline
\end{tabular}

Notes: Mean \pm SEM from four measurements, ANOVA, Student-Newman-Keuls method. Statistical significance: $* P \leq 0.05$ in comparison with PS.

Abbreviation: ANOVA, analysis of variance. adhesion plaques were usually relatively small, dot-like, and distributed on the ventral part of the cell membrane in its central region. On glass, these plaques were bigger, streaklike, and distributed in both peripheral and central parts of the cells (Figure 8A-C).

A similar morphology and distribution was also observed for vinculin-containing focal adhesion plaques, though they were usually smaller and less numerous than those containing talin (Figure 8D-F).

Beta-actin in cells on all three tested substrates was organized into fine fibers running in parallel between the opposite cell edges. These fibers were most apparent in cells on glass, while on both nanofibrous substrates, a considerable amount of $\beta$-actin was also distributed diffusely without forming specific structures (Figure 8G-I). 

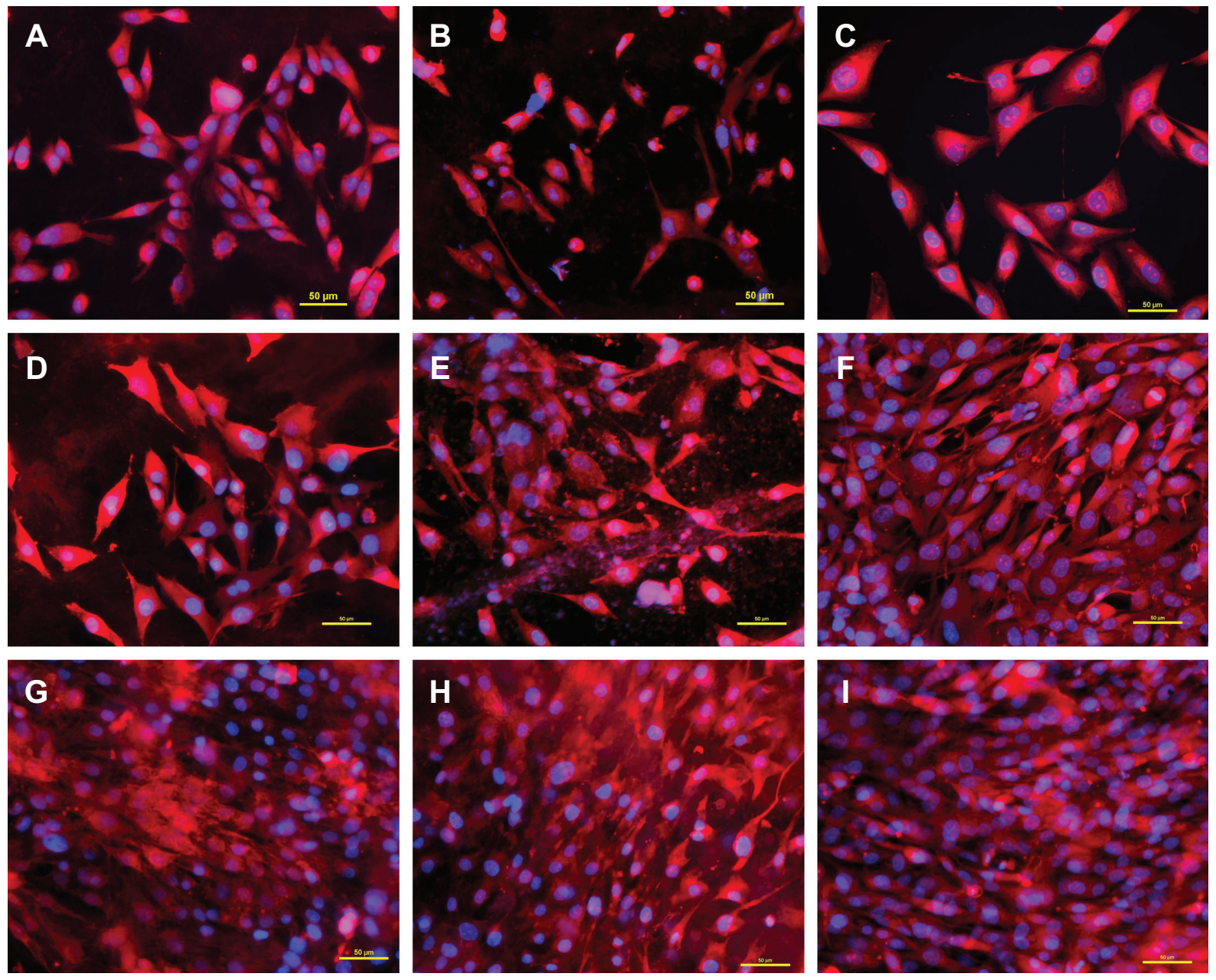

Figure 6 Morphology of human osteoblast-like MG-63 cells on days I (A-C), 3 (D-F), and 7 (G-I) after seeding on pure PLGA scaffolds (A, D, and G), composite PLGA-ND scaffolds (B, E, and $\mathbf{H}$ ), and a polystyrene culture well $(\mathbf{C}, \mathbf{F}$, and $\mathbf{I})$. The cell membrane and cytoplasm were stained with Texas Red $\mathrm{C}_{2}$-maleimide (red fluorescence), and the cell nuclei with Hoechst 33342 (blue fluorescence).

Notes: A Nikon Eclipse Ti-E microscope, objective $20 \times 1.5$; Nikon DS-Qil MC digital camera, NIS-Elements AR software, version 3.I0, were used. Summarization of Z-sections with deconvolution, bar $50 \mu \mathrm{m}$.

Abbreviations: PLGA, copolymer of L-lactide and glycolide; ND, nanodiamond.

\section{Immune activation of cells on nanofibrous membranes}

From days 2-7 after seeding of human osteoblast-like MG-63 cells on the tested materials, the concentration of human TNF- $\alpha$ in the culture medium ranged on average from 0.74 to $2.31 \mathrm{pg}$ per 100,000 cells. The concentration of TNF- $\alpha$ in the medium from PLGA, PLGA-ND, and PLGAHAp meshes was significantly higher than in the medium from control polystyrene dishes with and without CellCrowns (Figure 9C). The highest value $(2.31 \pm 0.21 \mathrm{pg} / 100,000$ cells $)$ was found in the medium taken from MG-63 cells on PLGA-ND meshes. Nevertheless, this concentration of TNF- $\alpha$ was very low. As follows from the calibration curve (Figure 9E), it was almost at the limit of detection by the human TNF- $\alpha$ Quantikine ELISA kit. Even after relatively long stimulation of MG-63 cells with a relatively high dose of bacterial lipopolysaccharide ( $10 \mu \mathrm{g} / \mathrm{mL}$ for 24 hours), the concentration of TNF- $\alpha$ in the culture medium reached only $5.07 \pm 0.24 \mathrm{pg} / 100,000$ cells, which still remained at the detection limit (Figure 9G).

On the other hand, the values obtained for RAW 264.7 macrophages were higher by $1-2$ orders of magnitude. On the tested samples, the concentration of TNF- $\alpha$ in the culture medium reached on average 12.9 to $51.1 \mathrm{pg} / 100,000$ cells. Similarly, as for MG-63 cells, the concentrations of TNF- $\alpha$ released into the culture medium by cells on all PLGA-based membranes were significantly higher than the values for control polystyrene wells. Nevertheless, the concentration of TNF- $\alpha$ released by the cells on PLGA-ND was similar as in cultures on pure PLGA (Figure 9D). The highest 

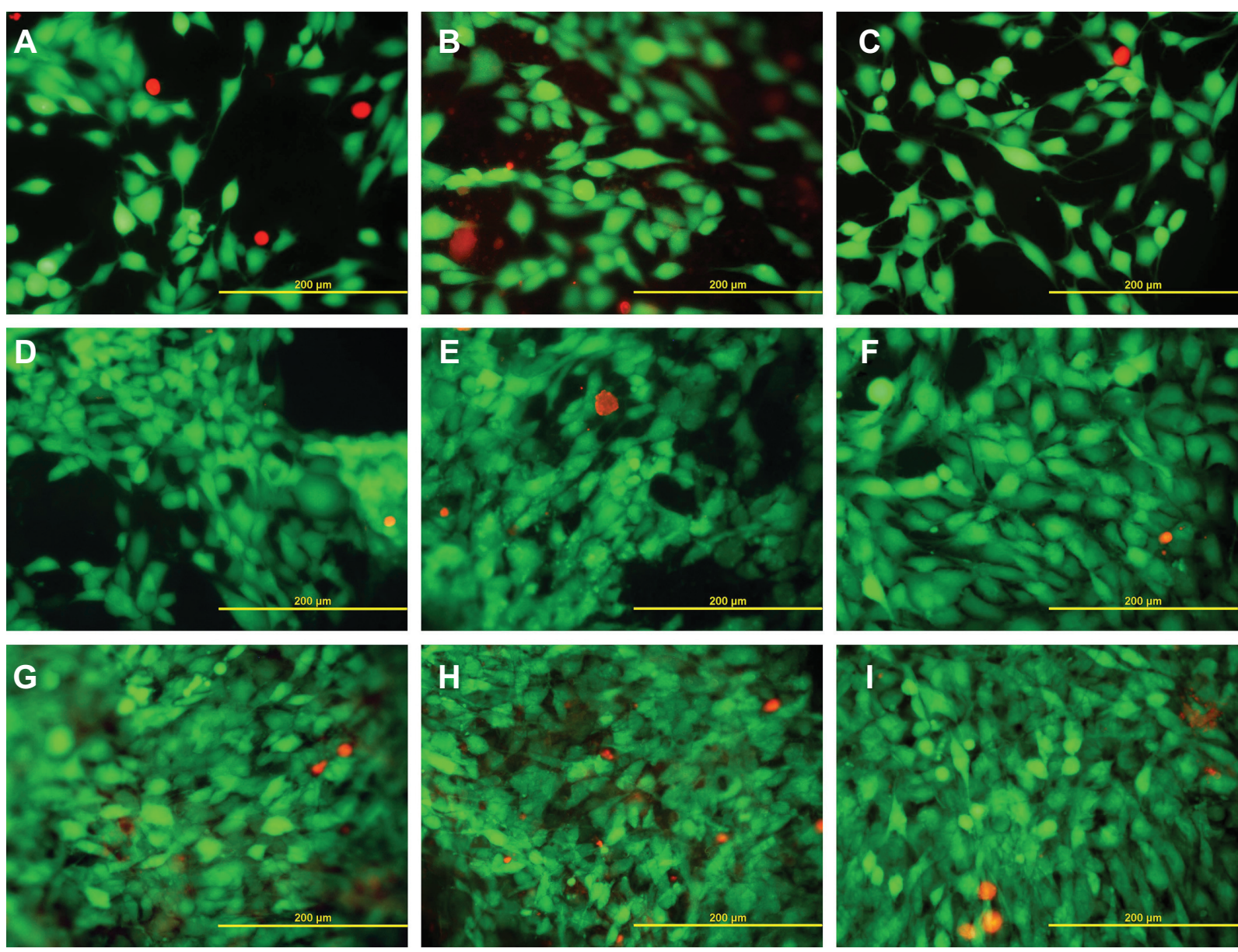

Figure 7 Live (green) and dead (red) human osteoblast-like MG-63 cells on days I (A-C), 3 (D-F), and 7 (G-I) after seeding on pure PLGA scaffolds (A, D, and G), composite PLGA-ND scaffolds (B, E, and $\mathbf{H})$ and a polystyrene culture well (C, F, and $\mathbf{I})$.

Notes: Stained with the LIVE/DEAD viability/cytotoxicity kit for mammalian cells. Olympus IX-5I, objective 20×, DP-70 digital camera, bar $200 \mu$ m.

Abbreviations: PLGA, copolymer of L-lactide and glycolide; ND, nanodiamond.

concentration (51.1 pg/100,000 cells) was obtained in the medium from PLGA-HAp membranes, and it was significantly higher than the values obtained in all other tested materials. In spite of this, it was much lower (about eight times) in comparison with the concentration of TNF- $\alpha$ released from RAW 264.7 cells after stimulation with the lowest concentration of lipopolysaccharide $(0.05 \mu \mathrm{g}$ of lipopolysaccharide, Figure 9H). For comparison, $10 \mu \mathrm{g} / \mathrm{mL}$ of lipopolysaccharide in our study induced a massive release of TNF- $\alpha$ from RAW 264.7 cells, manifested by a high concentration of TNF- $\alpha$ in the culture medium (731 \pm 7 pg/100,000 cells; Figure 9H). No TNF- $\alpha$ was detected in the pure culture media not exposed to cells, which served as a negative control.

As for ICAM-1, no significant differences in the concentration of this immunoglobulin in MG-63 cells or RAW 264.7 cells were detected on any tested materials (Figure 9I and J). In other words, all three types of PLGA-based membranes, ie, pure PLGA, PLGA-ND, and PLGA-HAp, did not evoke significantly higher concentrations of ICAM-1 in MG-63 or RAW 264.7 cells than the conventional cell culture system on polystyrene dishes.

\section{Discussion}

In this study, we constructed nanofibrous membranes by electrospinning pure PLGA or PLGA with approximately $23 \mathrm{wt} \%$ of ND. Recently, the first synthetic polymeric fibers of nanoscale or microscale diameter loaded with ND were created by Behler et a ${ }^{32}$ by electrospinning polyacrylonitrile or polyamide and ND powder produced via detonation synthesis. Similar to our study, the ND particles were not dispersed homogeneously in the polymeric matrix, but they formed agglomerates. However, these agglomerates were much smaller than those in our present study, ie, usually not exceeding the fiber diameter. At the same time, the concentration of ND particles reached $80 \mathrm{wt} \%$ in polyacrylonitrile, 

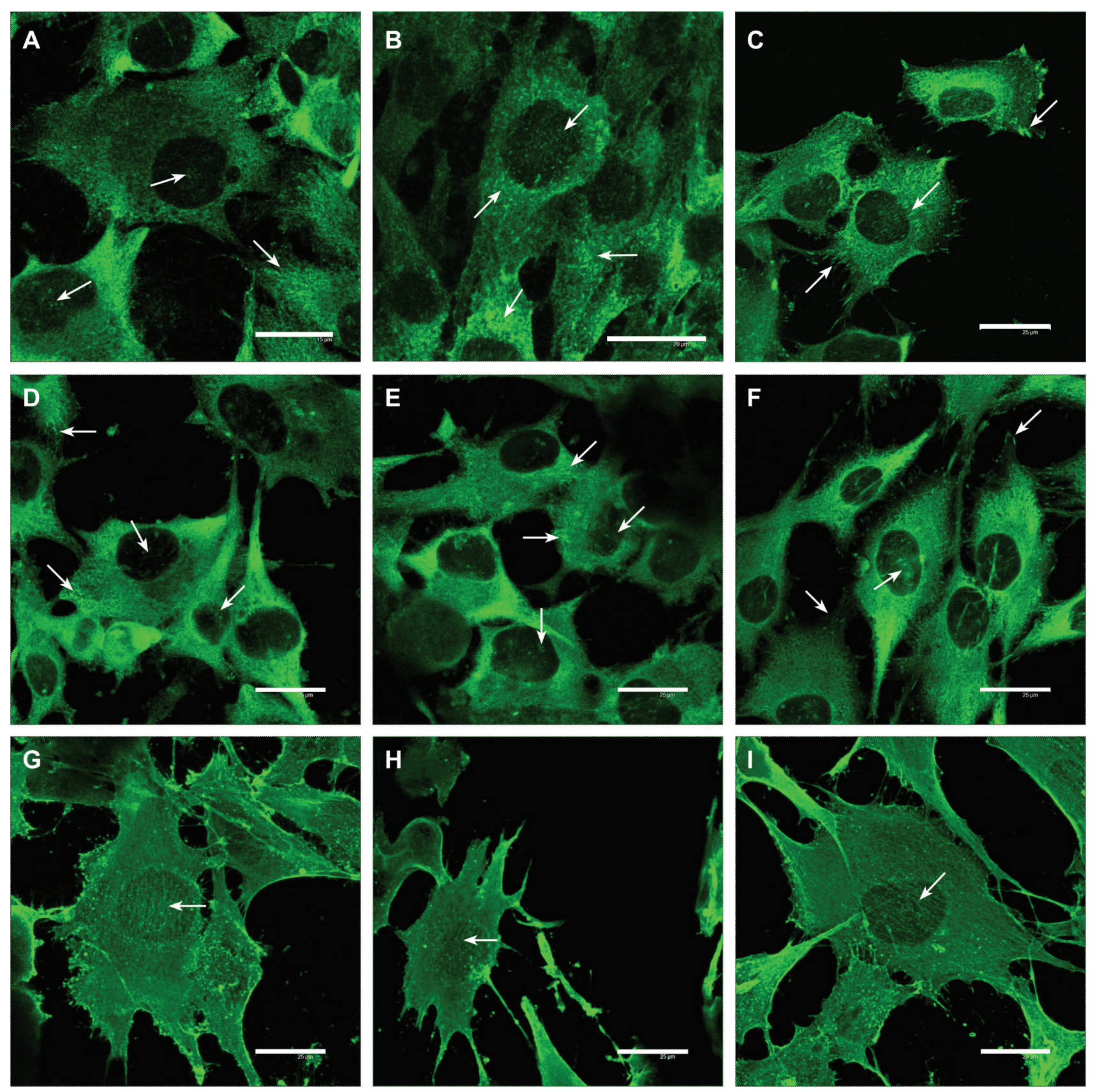

Figure 8 Immunofluorescence of talin (A-C), vinculin (D-F), and beta-actin (G-I) in human osteoblast-like MG-63 cells on day 3 after seeding on pure PLGA scaffolds (A, D, and $\mathbf{G})$, composite PLGA-ND scaffolds (B, E, and $\mathbf{H})$, and polystyrene culture well (C, F, and I).

Notes: Leica confocal laser scanning microscope (TCS SP2, Germany), objective 20×, zoom $8 \times$ (A) $8.5 \times$ (B), or $6 \times$ (remainder of pictures); bar $25 \mu \mathrm{m}$. Abbreviations: PLGA, copolymer of L-lactide and glycolide; ND, nanodiamond.

while on PLGA in our study, the concentration was only $23 \mathrm{wt} \%$. The optimum ND concentration for creating polyamide-based fibers was $40 \mathrm{wt} \%{ }^{32}$ The optimum ND concentration for forming composite fibers therefore seems to depend on the type of the polymer used. Other factors influencing ND agglomeration include sonication, stirring, and shaking the ND suspension, the diameter of the newly formed fibers, polymer surface tension, strength of the electrostatic forces pulling the fibers in electrospinning, type of solvent, and time of its evaporation. The concentrations of polymer and ND are also important. In the study by Behler et al, ${ }^{32}$ a relatively low polymer concentration $(6 \mathrm{wt} \%)$ in the solvent decreased the viscosity and increased the highest obtainable loading of ND. If the ND concentration increased above $20 \mathrm{wt} \%$, the fibers showed a more uniform distribution of these nanoparticles. On the other hand, excessively high 
A

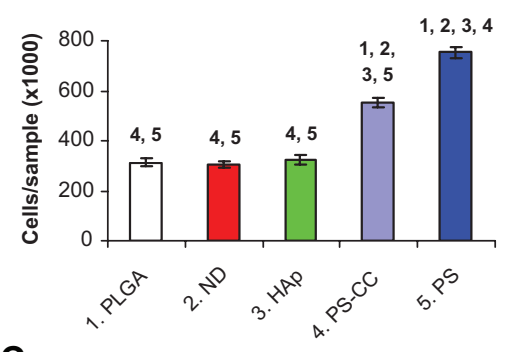

C

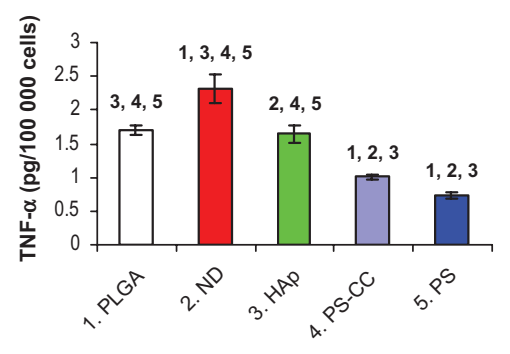

E

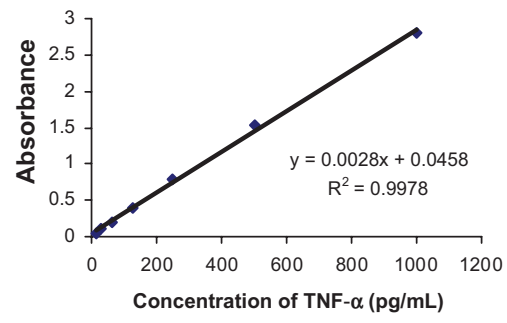

G

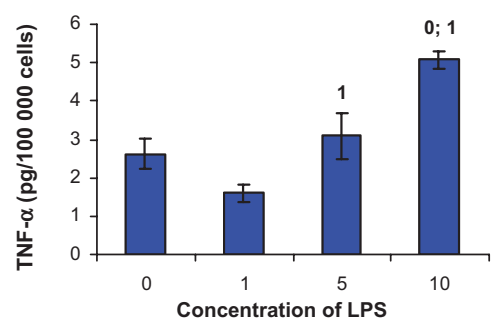

I

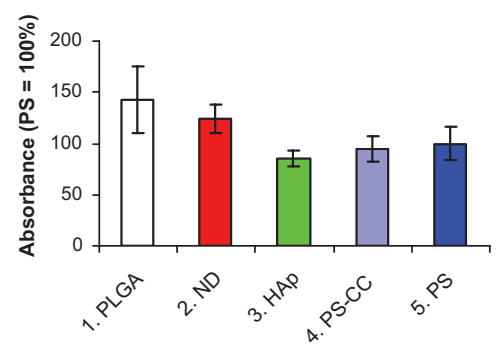

B

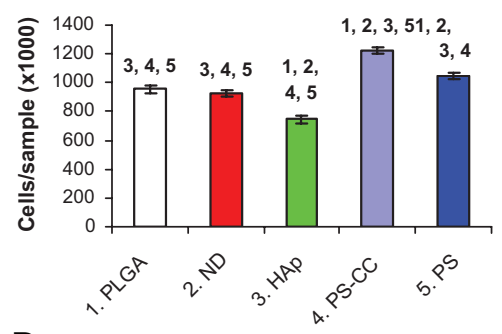

D

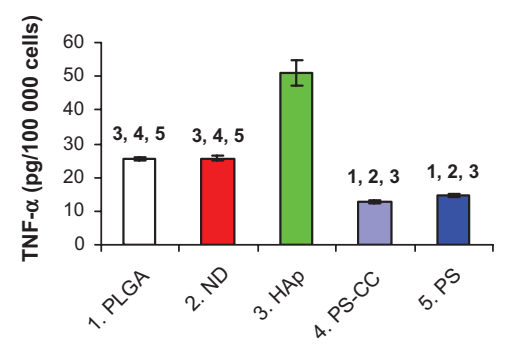

F

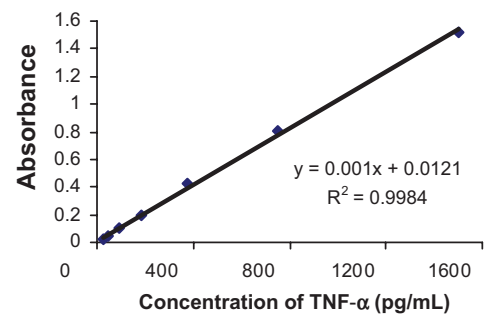

H

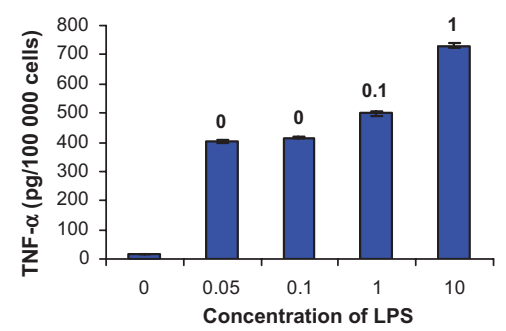

J

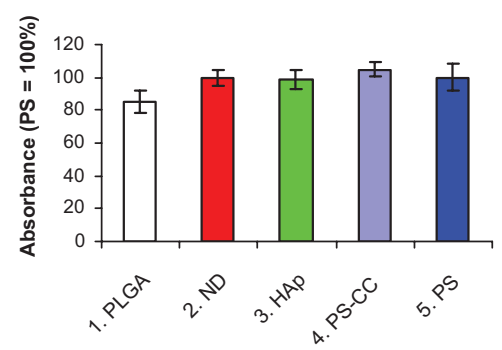

Figure 9 Markers of cell immune activation in human osteoblast-like MG-63 cells (A-I) and murine macrophage-like RAW 264.7 cells (B-J) on day 7 after seeding on pure nanofibrous PLGA membranes, PLGA membranes with ND, PLGA membranes with HAp, and bottom of polystyrene culture wells with and without CellCrown inserts (PS-CC and PS, respectively). (A and B) Cell number, with which the markers were correlated. (C and D) Concentration of TNF- $\alpha$ in the cell culture media taken from MG-63 or RAW 264.7 cells cultured on the tested materials. ( $E$ and $\mathbf{F}$ ) Calibration curves for TNF- $\alpha$ measured by human and mouse TNF- $\alpha$ Quantikine enzyme-linked immunosorbent assay kits, respectively. ( $\mathbf{G}$ and $\mathbf{H}$ ) Concentration of TNF- $\alpha$ in culture media taken from MG-63 or RAW 264.7 cells after 24-hours of stimulation with bacterial lipopolysaccharide $(0-10 \mu \mathrm{g} / \mathrm{mL})$. (I and J) Concentration of ICAM-I (per mg of protein) in homogenates of MG-63 or RAW 264.7 cells grown on the tested materials. Mean \pm standard error of the mean for four samples from each experimental group. In total, for each experimental group, 72 (A and B), eight (C, D, G, and H) or 24-26 (I and J) measurements were performed. Analysis of variance, Student-Newman-Keuls method. The numbers above the columns indicate the type of tested sample (A-D) or lipopolysaccharide concentration ( $\mathbf{G}$ and $\mathbf{H}$ ) with significantly different values.

Note: $P \leq 0.05$.

Abbreviations: PLGA, copolymer of L-lactide and glycolide; ND, nanodiamond; HAp, hydroxyapatite; PS, polystyrene; ICAM-I, intracellular adhesion molecule-I; LPS, lipopolysaccharide; TNF- $\alpha$, tumor necrosis factor alpha. 
concentrations of ND disabled the formation of fibers. An attempt to electrospin a $90 \mathrm{wt} \%$ ND-polyacrylonitrile composite resulted in electrospraying of droplets, in which most of the ND particles were agglomerated, and the clumps were connected with small fibers. ${ }^{32}$ In our study, a relatively low concentration of the polymer in the solvent was also used (ie, $2.3 \mathrm{wt} \%$ ), and the concentration of ND exceeded $20 \mathrm{wt} \%$ in the polymer, being $23 \mathrm{wt} \%$. Despite this, NDcontaining clusters were present in our meshes. Thus, additional factors should be taken into account, particularly the different setup of the electrospinning process. While in our study the membranes were formed purely by electrostatic forces, in the study by Behler et $\mathrm{al}^{32}$ these forces were potentiated by continuously pumping the ND dispersions through the syringe with a needle at $0.015 \mathrm{~cm} /$ minute. A similar technique, ie, a combination of an electrical field with active pumping and ejection of PLGA or PLA with HAp nanoparticles through a syringe with a needle, was also successfully used for electrospinning composite nanofibrous scaffolds for potential bone tissue engineering applications. ${ }^{9,12,14,15}$ In these studies, PLGA was dissolved in dichloromethane or 1,1,1,3,3,3-hexafluor-2-propanol at concentrations in the range of $2 \%-30 \% \mathrm{w} / \mathrm{v}$. The HAp particles were $100-200 \mathrm{~nm}$ in size, and they reached concentrations of $1-20 \mathrm{wt} \%$ in PLGA. At lower concentrations (up to $5 \mathrm{wt} \%$ ), the HAp nanoparticles were homogeneously dispersed inside or on the surface of PLGA fibers without forming clusters. At higher concentrations ( $10 \mathrm{wt} \%$ and especially $20 \mathrm{wt} \%$ ), HAp nanoparticles showed a tendency to agglomerate, which resulted in an increase in surface roughness, in porosity, and also in the fiber diameter. Good results were obtained with composite PLGA-tricalcium phosphate nanofibers, prepared by electrospinning $8 \%(\mathrm{w} / \mathrm{w})$ PLGA in chloroform, containing 5\% (w/w) of the surfactant Tween 20, and enriched with amorphous tricalcium phosphate (particle size 20-50 $\mathrm{nm}$ ) in concentrations of $10-40 \mathrm{wt} \%$ in PLGA. The tricalcium phosphate nanoparticles were homogeneously distributed in the PLGA matrix, although fractures on the fiber surface occurred at higher concentrations. ${ }^{13}$

As for the PLA-HAp composite fibers, PLA was dissolved in trifluoroethanol at a concentration of $10 \mathrm{wt} \%$, and the concentration of HAp nanoparticles (size $<100 \mathrm{~nm}$ ) ranged between $5 \mathrm{wt} \%$ and $20 \mathrm{wt} \%$ of PLA. At all concentrations, HAp nanoparticles were homogeneously distributed inside the nanofibers without forming aggregates and prominences on the fiber surface. ${ }^{9}$

A combination of PLA (dissolved in chloroform and dimethyl formamide at a ratio of $3: 1$ at a concentration of $20 \mathrm{wt} \%$ ) with multiwall carbon nanotubes (diameter $15 \pm 5 \mathrm{~nm}$ and length 5-20 $\mu \mathrm{m}$, concentration $1 \mathrm{wt} \%$ in PLA) also led to electrospinning of fibers with multiwall carbon nanotubes aligned with the long axis. Only occasional fibers with incompletely encapsulated MWNT were observed. ${ }^{23}$ Interestingly, nanocomposite PLA-multiwall carbon nanotubes fibers had a markedly smaller average diameter $(700 \mathrm{~nm})$ than PLA without multiwall carbon nanotubes (approximately 5-8 $\mu \mathrm{m}$ ). In contrast, when HAp nanoparticles were added to PLGA or PLA, the fiber diameter increased proportionally to the nanoparticle concentration, eg, from $300 \mathrm{~nm}$ (neat PLGA) to $700 \mathrm{~nm}$ (20\% nano-HAp). ${ }^{14}$ Also in our study, the PLGA-ND fibers were thicker than pure PLGA fibers (270 $\pm 9 \mathrm{~nm}$ versus $218 \pm 4 \mathrm{~nm}$ in diameter, Table 1).

Evaporation of the solvent during the electrospinning process is limited in the system using a needle and a syringe, whereas in our system a drop placed with a micropipette on the spike-like electrode was freely exposed to air. This allowed quick evaporation of the solvent and an increase in the polymer concentration and in the ND concentration in the dispersion. These changes may increase the viscosity of the dispersion, an important parameter which influences the spinnability of the materials. High viscosities are known to hamper electrospinning due to the flow instability caused by the high cohesiveness of the solution, while very low viscosities lead to the formation of droplets. ${ }^{17}$ Viscosity was not measured in our present study. However, the solution viscosity is proportional to polymer concentration. ${ }^{48,49}$ Polymer concentration plays a decisive role in the outcome of the electrospinning process: a low concentration led to the formation of beaded fibers; an intermediate concentration yielded good quality fibers; a high concentration resulted in a bimodal size distribution, and a distributed deposition at even higher concentration. ${ }^{49}$ In accordance with this, our preliminary experiments showed that a PLGA concentration of $2.3 \mathrm{wt} \%$ in the solvent enabled electrospinning of long and smooth nanofibers, whereas a relatively small decrease in this concentration to $2.0 \mathrm{wt} \%$ resulted in the formation of several $\mu \mathrm{m}$ large polymer clusters connected with a small number of short fibers (Figure 10), which may be due to low viscosity of the mixture. In a review article by Huang et al, ${ }^{17}$ a concentration of $5 \mathrm{wt} \%$ is recommended for PLGA. However, when the concentration of PLGA in our experiments was increased to $2.5 \mathrm{wt} \%$ or $3.0 \mathrm{wt} \%$, the results were also not ideal, ie, they were similar to the results obtained at the lower PLGA concentration of $2.0 \mathrm{wt} \%$.

As mentioned above, PLGA has often been dissolved in dichloromethane $^{12}$ or 1,1,1,3,3,3-hexafluor-2-propanol. . $^{10,14,15}$ 


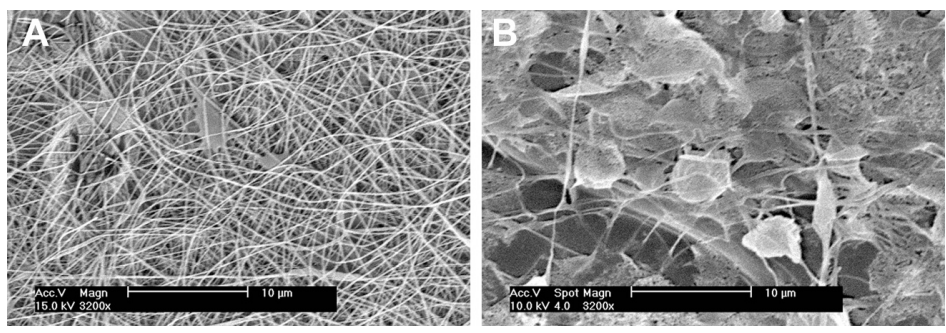

Figure 10 Morphology of nanofibrous PLGA scaffolds created by electrospinning of PLGA diluted in methylene chloride and dimethyl formamide (2:3) at a concentration of $2.3 \mathrm{wt} \%(\mathbf{A})$ or $2.0 \mathrm{wt} \%(\mathbf{B})$.

Note: XL30CP scanning electron microscope (Phillips Elektron Optics GmbH, Kassel, Germany), objective magnification 3200×, bar I0 $\mu$ m.

Abbreviation: PLGA, copolymer of L-lactide and glycolide.

Some investigators have also used N,N-dimethylformamide, ${ }^{50}$ chloroform, ${ }^{13}$ or a combination of tetrahydrofuran and N,Ndimethylformamide at a ratio of $1: 1^{17}$ or $3: 1 .^{11}$ In our preliminary experiments, a mixture of methylene chloride and N,N-dimethylformamide (ratio 2:3) proved to be the most appropriate solvent combination for our open-air electrospinning system. In this combination, methylene chloride is a relatively quickly evaporating solvent, while the evaporation of N,N-dimethylformamide is slower. Pure methylene chloride or other quickly evaporating solvents (ie, chloroform) did not give good results in our system, where the material, placed in a relatively small quantity on the top of the spikelike electrode, was freely exposed to air. From this point of view, the use of a pure slowly evaporating solvent (eg, N,Ndimethylformamide) seemed to be ideal. However, in our study, PLGA was less soluble in this type of solvent. Therefore, the abovementioned combination of quickly and slowly evaporating solvents was established in our study. In future experiments, we intend to use this combination in a Nanospider machine equipped with a bath-like vessel for the spun material instead of the experimental spike-like electrode used in this study. This "free liquid surface electrospinning" is expected to result in more effective production of nanofibrous meshes of excellent uniformity, controlled diameter of the nanofibers, and narrow fiber diameter distribution.

In addition to the properties of the polymer-solvent mixture, namely type and concentration of both polymer and solvent, evaporation of the solvent, type, size and concentration of the added nanoparticles, viscosity of the solution, and the forces pulling the nanofibers discussed above, other parameters are also important for successful electrospinning of nanofibers. In particular, these parameters include the voltage and the distance between the needle and target. During preparation of polycaprolactone nanofibers, the fiber length and diameter decreased with increasing voltage (10-20 kV), while the uniformity of the fibers increased. ${ }^{51}$ On the other hand, in the case of superelastic polymer ink formulations, the viscoelastic nature of these polymer inks enables continuous electrospinning at a very low voltage of $200 \mathrm{~V}^{52}$ As for the distance between the needle and target, when this distance is short, the electrospun fibers tend to stick to the collector as well as to each other, which is due to incomplete solvent evaporation. ${ }^{35}$ An increase in needle-collector distance represents a weaker electric field, a greater distance to be covered by the fibers and a longer flight time, presumably favoring the formation of thinner fibers. On the other hand, during electrospinning of poly(ethylene oxide), higher solvent evaporation led to a local increase of concentration and viscosity, and the viscoelastic forces opposing stretching caused an increase of fiber diameter with needle-collector distance. ${ }^{49}$

The number of initially adhering cells, their spreading area, their subsequent growth dynamics, and the numbers achieved on pure PLGA and composite PLGA-ND membranes in our study were similar. Although this is the first study on composite polymer-ND scaffolds used as growth supports for cells, and thus no comparison with studies by other authors is available, it is known that the addition of nanoparticles to polymeric nanofibrous scaffolds usually supports cell colonization of these materials. For example, on PLA-multiwalled carbon nanotube scaffolds, the number of human adipose-derived human mesenchymal stem cells on day 14 after seeding significantly exceeded the value on pure PLA fibers. This was attributed to the smaller diameter of PLA-multiwalled carbon nanotube fibers and smaller pores among them. In other words, there was a finer network which enabled the attachment of human mesenchymal stem cells at multiple focal points. ${ }^{23}$ In our study, the pores among the PLGA-ND fibers were also significantly smaller than in pure PLGA membranes. Thus, the cells bridged over smaller gaps and were able to come into more intense contact with the fibers. In accordance with these findings, the cells on PLGA-ND formed more numerous and more homogeneously distributed talin-containing focal adhesion plaques than the 
cells on pure PLGA membranes (Figure 8A and B). At the same time, these plaques were smaller (ie, finer) than those in cells on polystyrene dishes, particularly at the cell periphery. Streak-like and thick focal adhesion plaques have been considered as an artifact of the classical cell culture system, where the cells are cultivated on "two-dimensional" substrates such as polystyrene or glass under static conditions. ${ }^{53}$ Focal adhesion plaques of this type do not occur in tissues in vivo or in an advanced cell culture system with cells on "three-dimensional" substrates, including nanofibrous scaffolds, and cultured under dynamic conditions. From this point of view, the fine focal adhesion plaques in cells on nanofibrous meshes in our study can be considered as more physiological and better reflecting the morphology of focal adhesions on cells under in vivo conditions.

Another reason for the better developed talin-containing focal adhesion plaques on PLGA-ND membranes may be better mechanical properties of these membranes compared with pure PLGA scaffolds. Mechanically resistant materials are less deformed by tractional forces produced by the actin cytoskeleton, and thus they can better stimulate the cell spreading and assembly of focal adhesion plaques. ${ }^{54}$ In accordance with this, the rupture tests showed that PLGA-ND membranes were able to deform further and withstand a higher force than pure PLGA membranes. Two possible contributing factors to both these observations are the reinforcement of individual nanofibers by ND incorporation, which was demonstrated by transmission electron microscopy (Figure 2), and an increase in the number and strength of contacts between individual fibers by ND. Scanning electron microscopy images (Figure 1C and D) demonstrated that more material clusters were present in PLGA-ND membranes. It is conceivable that such clusters are reinforced by the presence of ND. Similarly, addition of nanodiamond has increased the hardness and stiffness of the polymer, polyvinyl alcohol, particularly in synergy with single-wall carbon nanotubes or graphene, ${ }^{55}$ and PLA ${ }^{33,46}$ Electrospun fibers of polyacrylonitrile also became harder and stiffer after incorporation of ND. ${ }^{32}$ However, to the best of our knowledge, this study is the first to demonstrate reinforcement of electrospun PLGA nanofibers by ND. The addition of ND to polymers has been proposed to cause reinforcement by interaction between functional groups on nanodiamond surfaces with polymer chains ${ }^{46}$ and an enhancement of polymer crystallinity. ${ }^{46,55}$ FTIR analysis revealed band shifts which were small compared with those observed by Zhao et al. ${ }^{46}$ One explanation is that the chemical interactions between PLGA and ND are weak. In this case, due to the weakness of these interactions, it would be expected that ND does not significantly increase the material crystallinity. This, in turn, would suggest that improved mechanical properties are due to an increased number of interfiber contacts in PLGA-ND membranes. Another explanation is that the concentration of ND is low at the surface and is thus not detected by FTIR, which is supported by the transmission electron microscopy images showing the presence of ND predominantly in the center of fibers. One cause for the "internalization" of ND is its poorer solubility compared with PLGA, leading to phase separation. Another factor is the lower size and therefore greater motility of the PLGA molecule compared with ND, allowing faster migration of PLGA to the fiber surface.

On the other hand, the more numerous and larger material clusters (often microsized) in the composite PLGA-ND membranes may hamper the adhesion, spreading, and growth of MG-63 cells on this material. In our earlier study, performed on bone MG-63 cells and vascular smooth muscle cells in cultures in carbon fiber-reinforced carbon composites, microsized irregularities distributed in microscale distances on the material surface exerted a negative influence on cell adhesion, spreading, and subsequent growth. ${ }^{56}$

Other nanoparticles have also been described to improve the mechanical properties (eg, their tensile modulus and tensile strength) and bioactivity of nanofibrous scaffolds made of synthetic polymers. These nanoparticles include multiwall carbon nanotubes, ${ }^{23}$ bioglass nanofibers, ${ }^{36}$ nanosized dispersed silica xerogel, ${ }^{37}$ tricalcium phosphate, ${ }^{13}$ and HAp. ${ }^{9,14}$ However, in PLGA-HAp composites, the material reinforcement by HAp occurred only at lower HAp concentrations (1-10 wt $\%$ ), whereas higher concentrations $(20 \mathrm{wt} \%)$ led to a decrease in storage modulus and fiber-breaking. ${ }^{14}$ On the other hand, a higher HAp concentration enhanced osteogenic differentiation of bone-forming cells. For example, the HAp component of PLGA/HAp composite nanofibers increased the activity of alkaline phosphatase, expression of osteogenic genes (eg, collagen, alkaline phosphatase, osteocalcin, bone sialoprotein), and calcium mineralization in human mesenchymal stem cells in cultures on these scaffolds. ${ }^{15}$ In addition, the release of BMP-2 from fibrous PLGA/HAp composite scaffolds was accelerated with increasing HAp content (5-10 wt $\%) .^{12}$ These positive findings have been explained by the hydrophilicity of HAp, by increased adsorption of cell adhesion-mediating proteins from the serum of the culture medium on HAp-containing scaffolds, and by the more rigid and spacious scaffold structure. ${ }^{12,15}$

Mechanical properties and bioactivity of nanofibrous scaffolds made of conventional polymers (ie, PLA) have been markedly improved by copolymerization with polyaniline. 
Recent publications by Gizdavic-Nikolaidis et $\mathrm{al}^{20,21}$ showed that functionalized polyaniline/PLA nanofibrous blends not only allow mammalian cells to attach and proliferate, but also kill pathogenic bacteria cells, and are novel conductive materials that are potentially well suited for use as biocompatible scaffolds for tissue engineering and as antimicrobial wound dressings that have the advantage of being able to kill microorganisms without use of an antiseptic.

The size of the cell spreading area, and the cell proliferation and cell population densities achieved on both PLGA and PLGA-ND scaffolds in our study were significantly lower than the values on the bottom of polystyrene wells. This may be due to the relatively small diameter of both PLGA and PLGA-ND fibers (on average $218 \mathrm{~nm}$ and $270 \mathrm{~nm}$, respectively), which limited the cell-material contact that is necessary for good colonization of a material with cells. In a study performed on NIH 3T3 fibroblasts in cultures on PLGA meshes, the cell spreading areas on meshes with fiber diameters of $140 \mathrm{~nm}$ and $760 \mathrm{~nm}$ were significantly lower than on continuous PLGA films, and were equal to the value on these films only at a fiber diameter of $3600 \mathrm{~nm} .{ }^{10}$ In a study by Kumbar et al, ${ }^{11}$ who created PLGA fibers from 150 to $6000 \mathrm{~nm}$ in diameter (by electrospinning PLGA in increasing concentrations), the range of the fiber diameter optimal for spreading, proliferation, and collagen III gene expression in human skin fibroblasts was 350-1100 nm. These findings were attributed to the optimum range of the material surface wettability (which increased with increasing fiber diameter), and a favorable cell-fiber interaction. ${ }^{11}$ The cell spreading on the nanofibrous membranes in our study may also be limited by the random orientation of the fibers in these scaffolds. It has been reported that increasing fiber orientation (from random to parallel) enlarged the cell spreading area. ${ }^{10}$

The increase in cell number on nanofibrous scaffolds in our study may also be reduced by lower viability of cells on these scaffolds in comparison with the values on the control polystyrene dishes. This lower cell viability may be due to limited cell-material contact and relatively small cell spreading areas. In anchorage-dependent cells, adequate contact with a material and spreading on it is decisive not only for proper functioning of the cells but primarily for survival of the cells. For example, human capillary endothelial cells cultured on fibronectin-coated islands larger than $1500 \mu \mathrm{m}^{2}$ spread and progressed through the cell cycle, whereas cells restricted to areas smaller than $500 \mu^{2}$ failed to extend and underwent apoptosis. ${ }^{57}$

In addition, on PLGA scaffolds loaded with ND, the cell viability on days 3 and 7 after seeding was lower than the cell viability on pure PLGA scaffolds. This may be attributed to a less favorable morphology of PLGA-ND meshes, ie, the presence of microsized clusters of ND, which could further hamper the cell-material contact. However, some adverse effects of the ND powder on cells also cannot be excluded. ND particles are generally considered to be noncytotoxic, nonimmunogenic, and nonallergenic. This is because there is no significant production of oxygen radicals by $\mathrm{ND}^{26,27}$ or even because ND has antioxidative effects. ${ }^{38}$ However, some authors have reported damaging effects of diamond nanoparticles on white and red blood cells in vitro and in vivo. ${ }^{58,59}$ This has been explained by the relatively high concentrations ( $1 \mathrm{mg} / \mathrm{mL}$ or more) of diamond nanoparticles used in these studies. In addition, ND powders often contain impurities, mainly other forms of carbon, such as graphite ${ }^{60}$ or iridium. ${ }^{39}$ The ND powder used in our study was grayish in color, which suggests the presence of these impurities. In our earlier study, performed on nanocrystalline diamond films, the presence of other carbon forms, namely graphite and amorphous carbon, was also indicated by Raman spectroscopy. ${ }^{28}$

The size of the diamond particles was also important for their potentially damaging effects on cells. In cultures of HeLa cells, microsized diamond crystals (diameter approximately $1 \mu \mathrm{m}$ ) caused considerable stress to the cells and attenuated their growth and viability. ${ }^{61}$ Microsized ND clusters in our PLGA-ND scaffolds might have similar effects, especially if they were released from the scaffolds and penetrated into the cells.

Nevertheless, cell viability above $90 \%$ can be considered as very high, comparable with the values in physiological cell populations, which also exhibit a certain cell turnover. In our earlier studies, focused on gender-related differences in the growth activity of rat aortic smooth muscle cells derived from male and female donors, cell loss (ie, spontaneous cell detachment often followed by cell death) in cultures of these cells on standard tissue culture polystyrene ranged from $3.0 \% \pm 1.4 \%$ to $22.4 \% \pm 1.7 \%{ }^{62}$

An important finding of this study was that the presence of diamond nanoparticles did not evoke any considerable inflammatory activation of osteoblast-like MG-63 cells and RAW 264.7 macrophages, as revealed by the concentrations of TNF- $\alpha$ in cell culture media and ICAM-1 in cell homogenates.

TNF- $\alpha$ is a cytokine involved in systemic inflammation and is a member of a group of cytokines that stimulate the acute phase reaction. It is produced mainly by activated macrophages, although it can be produced by other cell types as well, such as lymphoid cells, mast cells, endothelial cells, 
cardiac myocytes, adipose tissue, fibroblasts, cells of the nervous system, and also MG-63 cells. ${ }^{44,63}$ The release of TNF- $\alpha$ is highly stimulated by lipopolysaccharide, a component of the outer membrane of Gram-negative bacteria. ${ }^{63,64}$

ICAM-1, also referred to as CD54, is an immunoglobulin adhesion molecule in the cell membrane, which binds to $\beta_{2}$-integrin adhesion receptors on inflammatory cells (eg, leukocytes, monocytes, macrophages). It is expressed by leucocytes, macrophages, endothelial cells, and also by osteoblasts and osteoblast-like cell lines. ${ }^{65}$ Its expression can be induced by cytokines (TNF- $\alpha$ ) and is associated with osteoarthritis and osteoporosis. ${ }^{66,67}$

The concentration of TNF- $\alpha$ in the culture medium taken from MG-63 grown on PLGA-ND was significantly higher than in the media from pure PLGA, PLGA HAp, and control polystyrene cell culture wells. This increased cytokine production might be due to impurities in the ND powder, such as graphite and amorphous carbon. ${ }^{68,69}$ On the other hand, the production of TNF- $\alpha$ by MG-63 cells in our study can be quantified as very low and almost at the limit of detection by the human TNF- $\alpha$ Quantikine ELISA kit. Even after intensive stimulation of MG-63 cells with bacterial lipopolysaccharide, the concentration of TNF- $\alpha$ in the culture medium still remained at the detection limit, which suggests low sensitivity of MG-63 cells to inflammatory activation. In accordance with this finding, MG-63 and other human osteoblast-like cells, ie, SaOS-2, did not produce significant levels of TNF- $\alpha$ even after infection with Brucella abortus. A significant increase in TNF- $\alpha$ production (almost $600 \mathrm{pg}$ / $\mathrm{mL}$ of the culture medium) was achieved only in cocultures of these cells with human THP-1 monocytes. ${ }^{45}$ When RAW 264.7 macrophage-like cells, which are much more sensitive to the inflammatory activation than MG 63 cells, were used, the concentration of TNF- $\alpha$ in the cell culture medium from PLGA-ND samples (about 26 pg/100,000 cells, which corresponded to about $237 \mathrm{pg} / \mathrm{mL}$ of the medium) was similar to that in the medium from PLGA samples, and even lower than in the medium from PLGA-HAp. For comparison, after stimulation of RAW 264.7 macrophages with hydrogel particles $(0.03$ to $3 \mathrm{vol} \%)$ the concentration of TNF- $\alpha$ reached about $1000 \mathrm{pg} / \mathrm{mL}$ of the culture medium, and after stimulation with $0.1 \mu \mathrm{g} / \mathrm{mL}$ of lipopolysaccharide for 24 , it has reached more than $15,000 \mathrm{pg} / \mathrm{mL}^{44}$

Although the concentration of TNF- $\alpha$ released by RAW 264.7 cells grown on PLGA membranes with HAp was significantly higher than in cells on pure PLGA, PLGA-ND, and polystyrene wells in our study, HAp is generally considered to be a material with a relatively low inflammatory potential.
For example, RAW 264.7 macrophages in 24-hour cultures on a microfibrous composite of polyethylene terephthalate with $10 \mathrm{wt} \%$ of nanograde HAp released only $25 \mathrm{pg}$ of TNF- $\alpha$ per $\mathrm{mL}$ of culture medium, while after 24 hours of stimulation of these cells with $10 \mu \mathrm{g} / \mathrm{mL}$ of lipopolysaccharide, TNF- $\alpha$ concentrations reached $566 \mathrm{pg} / \mathrm{mL}^{70}$

In addition, the concentration of ICAM-1 in homogenates prepared from MG-63 or RAW 264.7 cells on PLGA-ND and PLGA-HAp membranes was also similar to that for cells on pure PLGA meshes and control polystyrene wells. Similar results were also obtained in our earlier studies on pure and boron-doped nanocrystalline diamond films. ${ }^{28}$ Thus, it can be concluded that the immune activation of cells on nanofibrous PLGA-ND membranes is very low, which correlates well with studies reporting no or a very low (and not significant) inflammatory reaction of cells and tissues in contact with ND particles. ${ }^{26,27,38}$ From this point of view, PLGA-ND composites seem to be a suitable material for bone tissue engineering.

\section{Conclusion and further perspectives}

Using an electrospinning technique, we constructed fibrous membranes made of pure PLGA and PLGA with $23 \mathrm{wt} \%$ of ND. The fiber diameter was $218 \pm 4 \mathrm{~nm}$ and $270 \pm 9 \mathrm{~nm}$, and the area of the pores among the fibers was $1.28 \pm 0.09 \mu^{2}$ in PLGA membranes and $0.46 \pm 0.02 \mu \mathrm{m}^{2}$ in PLGA-ND membranes. Both pure PLGA and composite PLGA-ND membranes supported attachment, spreading, subsequent proliferation, and viability of human osteoblast-like MG-63 cells in cultures on these materials, although the cell numbers were lower than on the control polystyrene dishes. This could be attributed to relatively thin fibers and numerous microsized clusters in these membranes, which could limit the cell-material contact and hamper cell spreading. Nevertheless, our composite PLGA-ND scaffolds showed improved mechanical properties and did not evoke a considerable inflammatory response. Thus, after several improvements, the PLGA-ND scaffolds could be applied as carriers for cells in bone tissue engineering. Investigations on the osteogenic differentiation of the cells on these scaffolds are in progress.

\section{Acknowledgments}

This study was supported by grants from the Academy of Sciences of the Czech Republic (KAN 400480701 and IAAX00100902), the Czech Science Foundation (106/09/1000 and P108/11/0794), the European Union (MyJoint Project, FP-6 NEST 028861), and the Research Foundation Flanders. TELD is supported by a Research Foundation Flanders 
postdoctoral fellowship. Robin Healey (Czech Technical University, Prague, Czech Republic) is gratefully acknowledged for his language revision of the manuscript.

\section{Disclosure}

The authors report no conflicts of interest in this work.

\section{References}

1. Webster TJ, Ergun C, Doremus RH, Siegel RW, Bizios R. Specific proteins mediate enhanced osteoblast adhesion on nanophase ceramics. J Biomed Mater Res. 2000;51:475-483.

2. Price RL, Waid MC, Haberstroh KM, Webster TJ. Selective bone cell adhesion on formulations containing carbon nanofibers. Biomaterials. 2003;24:1877-1887.

3. Boland ED, Matthews JA, Pawlowski KJ, Simpson DG, Wnek GE, Bowlin GL. Electrospinning collagen and elastin: preliminary vascular tissue engineering. Front Biosci. 2004;9:1422-1432.

4. Meinel AJ, Kubow KE, Klotzsch E, et al. Optimization strategies for electrospun silk fibroin tissue engineering scaffolds. Biomaterials. 2009;30:3058-3067.

5. Park YJ, Kim KH, Lee JY, et al. Immobilization of bone morphogenetic protein-2 on a nanofibrous chitosan membrane for enhanced guided bone regeneration. Biotechnol Appl Biochem. 2006;43: $17-24$.

6. Sargeant TD, Rao MS, Koh CY, Stupp SI. Covalent functionalization of NiTi surfaces with bioactive peptide amphiphile nanofibers. Biomaterials. 2008;29:1085-1098.

7. Stylianopoulos T, Bashur CA, Goldstein AS, Guelcher SA, Barocas VH. Computational predictions of the tensile properties of electrospun fiber meshes: effect of fiber diameter and fiber orientation. J Mech Behav Biomed Mater. 2008;1:326-335.

8. Pektok E, Nottelet B, Tille JC, et al. Degradation and healing characteristics of small-diameter poly(epsilon-caprolactone) vascular grafts in the rat systemic arterial circulation. Circulation. 2008;118: 2563-2570.

9. Jeong SI, Ko EK, Yum J, Jung CH, Lee YM, Shin H. Nanofibrous poly(lactic acid)/hydroxyapatite composite scaffolds for guided tissue regeneration. Macromol Biosci. 2008;8:328-338.

10. Bashur CA, Dahlgren LA, Goldstein AS. Effect of fiber diameter and orientation on fibroblast morphology and proliferation on electrospun poly(D,L-lactic-co-glycolic acid) meshes. Biomaterials. 2006;27: 5681-5688.

11. Kumbar SG, Nukavarapu SP, James R, Nair LS, Laurencin CT. Electrospun poly(lactic acid-co-glycolic acid) scaffolds for skin tissue engineering. Biomaterials. 2008;29:4100-4107.

12. Nie H, Soh BW, Fu YC, Wang CH. Three-dimensional fibrous PLGA/ HAp composite scaffold for BMP-2 delivery. Biotechnol Bioeng. 2008;99:223-34.

13. Schneider OD, Loher S, Brunner TJ, et al. Cotton wool-like nanocomposite biomaterials prepared by electrospinning: in vitro bioactivity and osteogenic differentiation of human mesenchymal stem cells. J Biomed Mater Res B Appl Biomater. 2008;84:350-362.

14. Jose MV, Thomas V, Johnson KT, Dean DR, Nyairo E. Aligned PLGA/ HA nanofibrous nanocomposite scaffolds for bone tissue engineering. Acta Biomater. 2009;5:305-315.

15. Lee JH, Rim NG, Jung HS, Shin H. Control of osteogenic differentiation and mineralization of human mesenchymal stem cells on composite nanofibers containing poly[lactic-co-(glycolic acid)] and hydroxyapatite. Macromol Biosci. 2010;10:173-182.

16. Pamula E, Filova E, Bacakova L, Lisa V, Adamczyk D. Resorbable polymeric scaffolds for bone tissue engineering: the influence of their microstructure on the growth of human osteoblast-like MG 63 cells. J Biomed Mater Res A. 2009;89:432-443.
17. Huang Z-M, Zhang Y-Z, Kotaki M, Ramakrishna S. A review on polymer nanofibers by electrospinning and their applications in nanocomposites. Compos Sci Technol. 2003;63:2223-2253.

18. Vasita R, Katti DS. Nanofibers and their applications in tissue engineering. Int J Nanomedicine. 2006;1:15-30.

19. Tan J, Saltzman WM. Biomaterials with hierarchically defined microand nanoscale structure. Biomaterials. 2004;25:3593-3601.

20. Gizdavic-Nikolaidis M, Ray S, Bennett JR, Easteal AJ, Cooney RP. Electrospun functionalized polyaniline copolymer-based nanofibers with potential application in tissue engineering. Macromol Biosci. 2010;10:1424-1431.

21. Gizdavic-Nikolaidis MR, Bennett JR, Swift S, Ray S, Bowmaker G. Electrospun poly(aniline-co-ethyl 3-aminobenzoate)/poly(lactic acid) nanofibers and their potential in biomedical application. J Polym Sci A Polym Chem. 2011;49:4902-4910.

22. Kim HW, Lee HH, Chun GS. Bioactivity and osteoblast responses of novel biomedical nanocomposites of bioactive glass nanofiber filled poly(lactic acid). J Biomed Mater Res A. 2008;85:651-663.

23. McCullen SD, Stevens DR, Roberts WA, et al. Characterization of electrospun nanocomposite scaffolds and biocompatibility with adiposederived human mesenchymal stem cells. Int J Nanomedicine. 2007;2:253-263.

24. Sargent LM, Reynolds SH, Castranova V. Potential pulmonary effects of engineered carbon nanotubes: in vitro genotoxic effects. Nanotoxicology. 2010;4:396-408.

25. Wang L, Luanpitpong S, Castranova V, et al. Carbon nanotubes induce malignant transformation and tumorigenesis of human lung epithelial cells. Nano Lett. 2011;11:2796-2803.

26. Schrand AM, Huang H, Carlson C, et al. Are diamond nanoparticles cytotoxic? J Phys Chem B. 2007;111:2-7.

27. Amaral M, Dias AG, Gomes PS, et al. Nanocrystalline diamond: in vitro biocompatibility assessment by MG 63 and human bone marrow cells cultures. J Biomater Res A. 2008;87:91-99.

28. Grausova L, Kromka A, Burdikova Z, et al. Enhanced growth and osteogenic differentiation of human osteoblast-like cells on boron-doped nanocrystalline diamond thin films. PLoS One. 2011;6:e20943.

29. Liu KK, Wang CC, Cheng CL, Chao JI. Endocytic carboxylated nanodiamond for the labeling and tracking of cell division and differentiation in cancer and stem cells. Biomaterials. 2009;30:4249-4259.

30. McDevitt MR, Chattopadhyay D, Jaggi JS, et al. PET imaging of soluble yttrium-86-labeled carbon nanotubes in mice. PLoS One. 2007;2:e907.

31. Ruggiero A, Villa CH, Bander E, et al. Paradoxical glomerular filtration of carbon nanotubes. Proc Natl Acad Sci U S A. 2010;107: 12369-12374.

32. Behler KD, Stravato A, Mochalin V, Korneva G, Yushin G, Gogotsi Y. Nanodiamond-polymer composite fibers and coatings. ACS Nano. 2009;3:363-369.

33. Zhang Q, Mochalin VN, Neitzel I, et al. Fluorescent PLLA-nanodiamond composites for bone tissue engineering. Biomaterials. 2011;32:87-94.

34. Dos Santos AM, Dierck J, Troch M, Podevijn M, Schacht E. Production of continuous electrospun mats with improved mechanical properties. Macromol Mater Eng. 2011;296:637-644.

35. Huang L, Nagapudi K, Apkarian RP, Chaikof EL. Engineered collagenPEO nanofibers and fabrics. J Biomater Sci Polym Ed. 2001; 12:979-993.

36. Jo JH, Lee EJ, Shin DS, et al. In vitro/in vivo biocompatibility and mechanical properties of bioactive glass nanofiber and poly(epsiloncaprolactone) composite materials. J Biomed Mater Res B Appl Biomater. 2009;91:213-220.

37. Jang TS, Lee EJ, Jo JH, et al. Fibrous membrane of nano-hybrid polyL-lactic acid/silica xerogel for guided bone regeneration. J Biomed Mater Res B Appl Biomater. 2011 Nov 21. [Epub ahead of print.]

38. Mitura S, Mitura K, Niedzielski P, Louda P, Danilenko V. Nanocrystalline diamond, its synthesis, properties and applications. J AMME. 2006; 16:9-16. 
39. Kromka A, Rezek B, Remes Z, et al. Formation of continuous nanocrystalline diamond layer on glass and silicon at low temperatures. Chem Vapor Depos. 2008;14:181-186.

40. Kromka A, Rezek B, Kalbacova M, et al. Diamond seeding and growth of hierarchically structured films for tissue engineering. Adv Eng Mater. 2009;11:B71-B76.

41. Kromka A, Babchenko O, Kozak H, Rezek B, Vanecek M. Role of polymers in CVD growth of nanocrystalline diamond films on foreign substrates. Phys Stat Sol B. 2009;246:2654-2657.

42. Janicki P, Boeuf S, Steck E, Egermann M, Kasten P, Richter W. Prediction of in vivo bone forming potency of bone marrow-derived human mesenchymal stem cells. Eur Cell Mater. 2011;21:488-507.

43. Maheshwari G, Brown G, Lauffenburger DA, Wells A, Griffith LG. Cell adhesion and motility depend on nanoscale RGD clustering. J Cell Sci. 2000;113:1677-1686.

44. Yim ES, Zhao B, Myung D, et al. Biocompatibility of poly(ethylene glycol)/poly(acrylic acid) interpenetrating polymer network hydrogel particles in RAW 264.7 macrophage and MG-63 osteoblast cell lines. J Biomed Mater Res A. 2009;91:894-902.

45. Delpino MV, Fossati CA, Baldi PC. Proinflammatory response of human osteoblastic cell lines and osteoblast-monocyte interaction upon infection with Brucella spp. Infect Immun. 2009;77:984-895.

46. Zhao Y-Q, Lau K-T, Kim J-K, Xu C-L, Zhao D-D, Li H-L. Nanodiamond/poly (lactic acid) nanocomposites: Effect of nanodiamond on structure and properties of poly (lactic acid). Composites: Part B. 2010;41:646-653.

47. Jose MV, Thomas V, Dean DR, Nyairo E. Fabrication and characterization of aligned nanofibrous PLGA/collagen blends as bone tissue scaffolds. Polymer. 2009;50:3778-3785.

48. Deitzel JM, Kleinmeyer J, Harris D, Beck Tan NC. A review on polymer nanofibers by electrospinning and their applications in nanocomposites. J Nanosci Nanotechnol. 2009;9:3535-3545.

49. Henriques C, Vidinha R, Botequim D, Borges JP, Silva JA. A systematic study of solution and processing parameters on nanofiber morphology using a new electrospinning apparatus. J Nanosci Nanotechnol. 2009;9:3535-3545.

50. Liang D, Luu YK, Kim K, Hsiao BS, Hadjiargyrou M, Chu B. In vitro non-viral gene delivery with nanofibrous scaffolds. Nucleic Acids Res. 2005;33:e170.

51. Beachley V, Wen X. Effect of electrospinning parameters on the nanofiber diameter and length. Mater Sci Eng C Mater Biol Appl. 2009;29: 663-668

52. Bisht GS, Canton G, Mirsepassi A, et al. Controlled continuous patterning of polymeric nanofibers on three-dimensional substrates using lowvoltage near-field electrospinning. Nano Lett. 2011;11:1831-1837.

53. Hu J, Liu X, Ma PX. Induction of osteoblast differentiation phenotype on poly(L-lactic acid) nanofibrous matrix. Biomaterials. 2008;29: 3815-3821.

54. Engler A, Bacakova L, Newman C, Hategan A, Griffin M, Discher D. Substrate compliance versus ligand density in cell on gel responses. Biophys J. 2004;86:617-628.

55. Prasad KE, Das B, Maitra U, Ramamurty U, Rao CN. Extraordinary synergy in the mechanical properties of polymer matrix composites reinforced with 2 nanocarbons. Proc Natl Acad Sci U S A. 2009;106: 13186-13189.
56. Bacakova L, Stary V, Kofronova O, Lisa V. Polishing and coating carbon fiber-reinforced carbon composites with a carbon-titanium layer enhances adhesion and growth of osteoblast-like MG63 cells and vascular smooth muscle cells in vitro. J Biomed Mater Res. 2001;54: $567-578$.

57. Huang S, Chen CS, Ingber DE. Control of cyclin D1, p27(Kip1), and cell cycle progression in human capillary endothelial cells by cell shape and cytoskeletal tension. Mol Biol Cell. 1998;9:3179-3193.

58. Puzyr AP, Neshumaev DA, Tarskikh SV, Makarskaia GV, Dolmatov VI, Bondar VS. Destruction of human blood cells upon interaction with detonation nanodiamonds in experiments in vitro. Biofizika. 2005;50.101-106. Russian.

59. Karpukhin AV, Avkhacheva NV, Yakovlev RY, et al. Effect of detonation nanodiamonds on phagocyte activity. Cell Biol Int. 2011;35:727-733.

60. Krueger A. New carbon materials: biological applications of functionalized nanodiamond materials. Chemistry. 2008;14:1382-1390.

61. Fucikova A, Valenta J, Pelant I, Brezina V. Novel use of silicon nanocrystals and nanodiamonds in biology. Chem Pap. 2009;63:704-708.

62. Bacakova L, Mares V, Lisa V, Bottone MG, Pellicciari C, Kocourek F. Sex-related differences in the migration and proliferation of rat aortic smooth muscle cells in short and long term culture. In Vitro Cell Dev Biol. 1997;33:410-413.

63. Huang TH, Lu YC, Kao CT. Low-level diode laser therapy reduces lipopolysaccharide (LPS)-induced bone cell inflammation. Lasers Med Sci. October 16, 2011. [Epub ahead of print.]

64. Takaoka Y, Matsuura S, Boda K, Nagai H. The effect of mesoporphyrin on the production of cytokines by inflammatory cells in vitro. Jpn J Pharmacol. 1999;80:33-40.

65. Kurokouchi K, Kambe F, Kikumori T, et al. Effects of glucocorticoids on tumor necrosis factor alpha-dependent activation of nuclear factor kappaB and expression of the intercellular adhesion molecule 1 gene in osteoblast-like ROS17/2.8 cells. J Bone Miner Res. 2000;15: 1707-1715.

66. Shi Q, Benderdour M, Lavigne P, Ranger P, Fernandes JC. Evidence for two distinct pathways in TNFalpha-induced membrane and soluble forms of ICAM-1 in human osteoblast-like cells isolated from osteoarthritic patients. Osteoarthritis Cartilage. 2007;15:300-308.

67. Tanaka Y, Maruo A, Fujii K, et al. Intercellular adhesion molecule 1 discriminates functionally different populations of human osteoblasts: characteristic involvement of cell cycle regulators. J Bone Miner Res. 2000;15:1912-1923.

68. Whitehead GS, Grasman KA, Kimmel EC. Lung function and airway inflammation in rats following exposure to combustion products of carbon-graphite/epoxy composite material: comparison to a rodent model of acute lung injury. Toxicology. 2003;183:175-197.

69. Li Q, Xia YY, Tang JC, Wang RY, Bei CY, Zeng Y. In vitro and in vivo biocompatibility investigation of diamond-like carbon coated nickel-titanium shape memory alloy. Artif Cells Blood Substit Immobil Biotechnol. 2011;39:137-142.

70. Dimitrievska S, Petit A, Ajji A, Bureau MN, Yahia L. Biocompatibility of novel polymer-apatite nanocomposite fibers. J Biomed Mater Res A. 2008;84:44-53.
International Journal of Nanomedicine

\section{Publish your work in this journal}

The International Journal of Nanomedicine is an international, peerreviewed journal focusing on the application of nanotechnology in diagnostics, therapeutics, and drug delivery systems throughout the biomedical field. This journal is indexed on PubMed Central, MedLine, CAS, SciSearch $®$, Current Contents $₫ /$ Clinical Medicine, Journal

\section{Dovepress}

Citation Reports/Science Edition, EMBase, Scopus and the Elsevier Bibliographic databases. The manuscript management system is completely online and includes a very quick and fair peer-review system, which is all easy to use. Visit http://www.dovepress.com/ testimonials.php to read real quotes from published authors. 